Chapter 8

\title{
A review of Corrosion Resistance Nanocomposite Coatings
}

\author{
Thais G.L. Rezende, Deborah V. Cesar, Dalva C.B. do Lago and \\ Lilian F. Senna
}

Additional information is available at the end of the chapter

http://dx.doi.org/10.5772/62048

\begin{abstract}
The deterioration of materials, particularly metals, under the influence of electrochemical corrosion is a high cost problem faced by nearly all industries. The reduction of corrosion processes and the prevention of future problems require a detailed knowledge of these processes and of the strategies to avoid them. In this context, it is essential to use methodologies that may prevent the electrochemical deterioration of materials as well as monitor their performance in aggressive environments. Among them, it is possible to cite the use of functional coatings, particularly nanocomposite coatings. Therefore, this chapter proposes a review concerning the production of nanocomposite coatings with anticorrosive application obtained by electrodeposition technique (electrochemical codeposition). The production of such coatings is in agreement with the current needs of innovation, which drives a requirement for scientific advancement and the need for fundamental research. In this context, nanocomposite coatings with anticorrosive properties promote changes in metal surfaces, creating new materials with improved characteristics compared to those originally observed and maintaining the integrity of these surfaces.
\end{abstract}

Keywords: Corrosion resistance, mechanical characteristics, nanocomposite coatings, electrochemical codeposition, metallic matrix composite

\section{Introduction}

It is known that corrosive processes handle many failures and accidents, involving among other drawbacks, environmental damage, and stops in the production with high economic losses. The monitoring and prevention of corrosion processes of materials in industrial plants is a worldwide need, improving the development of new (or advanced) materials, modified surfaces, and engineering processes. The conception of advanced materials is directly linked 
to investigations involving the production, degradation, and, consequently, ways to protect materials. In addition, environmental requirements considering technologies and processes must also be considered.

Functional coatings are so called because they present an additional functionality (such as corrosion protection, improved mechanical resistance or abrasion resistance, and thermal or electrical conductivity/isolation) besides their usual decorative or protection properties. These coatings are generally used to modify the surface of a substrate producing materials with enhanced or even new properties compared to those presented by the substrate itself [1-3]. Thus, depending on the application, several different ceramic, metallic, polymeric, or composite functional coating/substrate systems with own characteristics can be produced by different techniques [1,2].

The coatings constituted by a metallic matrix containing a second phase of a polymeric, metallic, or ceramic material are called metallic matrix composite coatings (MMC coatings) [4]. The second-phase materials are most commonly added to the metallic matrix as particles or nanowires, whose nature depends on the properties required for the development and application of the MMC coatings, based on the association properties of the particle and the matrix [5]. The materials most used as a second phase in $\mathrm{MMC}$ coatings are $\mathrm{Al}_{2} \mathrm{O}_{3}, \mathrm{TiO}_{2}, \mathrm{SiO}_{2}$, $\mathrm{Cr}_{2} \mathrm{O}_{3}, \mathrm{ZrO}_{2}, \mathrm{WC}, \mathrm{SiC}$, polystyrene, talc, and $\mathrm{MoS}_{2}$, in sizes ranging from micrometers to nanometers [6-8]. The use of these coatings for corrosion application will be the subject more deeply discussed in this chapter.

MMC coatings containing ceramic nanoparticles are very useful for advanced surface finishing applications, presenting wide application in engineering processes. The dispersion of hard nanoparticles, such as silicon carbide, silica, and alumina, or of nonmetallic nanowires on a metal matrix can yield materials with improved properties, such as hardness, wear and corrosion resistances, self-lubrication, and higher temperature stability, compared to single metal or even alloy metallic coatings [9]. High-pressure valves, drilling and car accessories, engineering and aerospace precision devices, medical, marine, and agriculture devices, mining and nuclear apparatus, microelectronics, corrosion protection for lubrication in sliding electrical contacts, and aircraft systems are some examples of fields in which these coatings are used $[10,11]$.

The literature describes various techniques to produce functional MMC coatings, such as physical vapor deposition (PVD), chemical vapor deposition (CVD), chemical reduction (CR) or electroless process, dip coating, thermal spraying (TS), brush plating (painting) (BP), electrophoretic deposition, and electroplating (electrochemical codeposition). All of these processes aim to achieve coatings with improved uniformity, good reproducibility, high adhesion, high deposition rate, low roughness, and low cost [12-15]. It is important to mention that these features, as well as the coating morphology and microstructure, the incorporated particle size (particle clusters), and the amount of particle in the coating, depend on both the substrate and the deposition process used to produce the MMC coatings, influencing the properties of the coating/substrate system [16-22]. Table 1 presents some examples of MMC coatings produced with different deposition processes and the main results achieved by the researchers. As the present revision concerns about the corrosion resistance of nanocomposite coatings, only the coatings produced on metallic substrates will be considered. 


\begin{tabular}{|c|c|c|c|c|c|}
\hline $\begin{array}{l}\text { Deposition } \\
\text { process }\end{array}$ & Substrate & $\begin{array}{l}\text { Metallic } \\
\text { matrix }\end{array}$ & Second phase & Main features & Ref. \\
\hline CVD & AISI 316L steel & Ni powders & $\begin{array}{l}\mathrm{B}_{4} \mathrm{C} \text {, with } 35 \\
\text { and } 140 \mu \mathrm{m}\end{array}$ & $\begin{array}{l}\text { - Particle agglomeration; } \\
\text { - The formed single layer of nickel } \\
\text { had lamellar structure; } \\
\text { - The coatings produced from the } \\
\text { smaller particles show higher } \\
\text { hardness and higher } \mathrm{B}_{4} \mathrm{C} \text { content than } \\
\text { the coatings produced with the } \\
\text { coarse particle size }\end{array}$ & [16] \\
\hline CR & Steel & $\mathrm{Cu}$ & $\begin{array}{l}\mathrm{SiC} \text { and } \\
\text { graphite }\left(\mathrm{C}_{\mathrm{g}}\right) \text {, } \\
\text { ranging from } 4 \\
\text { to } 10 \mu \mathrm{m}\end{array}$ & $\begin{array}{l}\text { - Coating thickness of approximately } \\
5 \mu \mathrm{m} \text { were obtained; } \\
\text { - Different phases, depending on } \\
\text { which particle was used; } \\
\text { - The Cu-P-SiC coatings had higher } \\
\text { hardness ( } 280 \pm 1 \mathrm{HV} \text { ) than the Cu-P } \\
\text { coating ( } 190 \pm 1 \mathrm{HV} \text { ); } \\
\text { - The coefficient of friction and } \\
\text { surface energy of Cu-P-C } \mathrm{C}_{\mathrm{g}} \text { coatings } \\
(0.225 \pm 0.012) \text { was smaller than that of } \\
\text { Cu-P coatings ( } 0.302 \pm 0.023) \text {; } \\
\text { - Cu-P-SiC-C } \text { g coatings showed the } \\
\text { combinations of Cu-P-SiC (high } \\
\text { hardness, } 183 \pm 1 \mathrm{HV)} \text { and Cu-P-C } \\
\text { (low friction coefficient, } 0.014 \pm 0272 \text { ) } \\
\text { coating properties }\end{array}$ & [18] \\
\hline TS & $\begin{array}{l}\text { AZ91D Mg } \\
\text { alloy }\end{array}$ & $\mathrm{Al}$ & $\begin{array}{l}\alpha-\mathrm{Al}_{2} \mathrm{O}_{3} \text {, } \\
\text { ranging from } 1 \\
\text { to } 30 \mu \mathrm{m}\end{array}$ & $\begin{array}{l}\text { - Coatings containing either } 25 \text { or } 50 \\
\text { wt } \% \alpha-\mathrm{Al}_{2} \mathrm{O}_{3} \text { particles had lower } \\
\text { porosity and better adhesion } \\
\text { compared to pure aluminum coating; } \\
\text { - The corrosion current densities }\left(\mathrm{j}_{\text {corr }} \text { ) }\right. \\
\text { of these composite coatings ( } \mathrm{j}_{\text {corr }}= \\
1.6 \times 10^{-7} \text { and } 3.0 \times 10^{-7} \mathrm{~A} \mathrm{~m}^{-2} \text { for } 25 \text { and } \\
50 \mathrm{wt} \% \alpha-\mathrm{Al}_{2} \mathrm{O}_{3} \text { ) were not different } \\
\text { from the value obtained for the pure } \\
\text { aluminum coating }\left(\mathrm{j}_{\text {corr }}=4.6 \times 10^{-7} \mathrm{~A}\right. \\
\mathrm{m}^{-2} \text { ) }\end{array}$ & [20] \\
\hline BP & Steel & $\mathrm{Ni}$ & Nano- $\mathrm{Al}_{2} \mathrm{O}_{3}$ & $\begin{array}{l}\text { - Coating thickness of } 50 \mu \mathrm{m} \text { was } \\
\text { obtained; } \\
\text { - Coatings with smooth, dense, and } \\
\text { uniform morphology were obtained }\end{array}$ & [21] \\
\hline
\end{tabular}




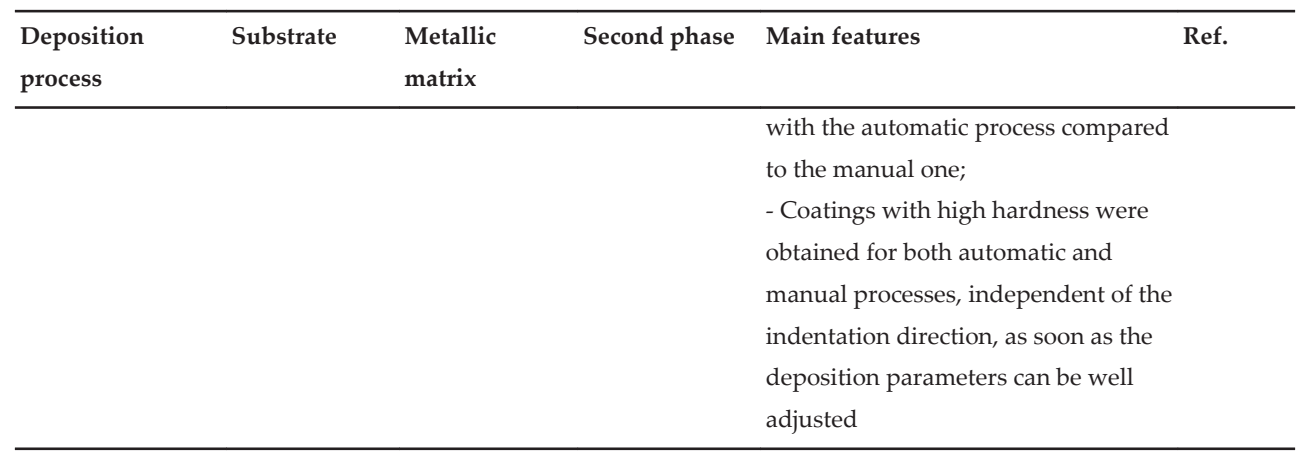

Table 1. Examples of MMC coatings produced by different deposition processes.

Although all of the aforementioned processes may be used to produce functional MMC coatings, the most widely used production method is electrochemical codeposition, also known as electrocodeposition, which consists of incorporating nanoparticles or nanowires (generally nonmetallic ones) intentionally added to the electrolyte to the metallic matrix during the electrodeposition process. This technique has been under investigation for several decades, and some authors have proposed models to explain the codeposition phenomenon of the particles during the formation of a cathodic deposit by electrodeposition [6,8,11,23-25]. This topic is still up to date because the process is more complex than the traditional electrodeposition and no commercial electrochemical baths have been developed so far for industrial production of these types of composite coatings. The main parameters that affect the process (e.g., solution $\mathrm{pH}$, stirring speed, and current density) were related; however, there is no consensus in the literature concerning their effects in the nanoparticle content in the coating and in the anticorrosive performance of the coating/substrate system [5,6,8,11,12,17,23,26-28]. It is also necessary that the nanoparticles be maintained suspended and dispersed (nonagglomerated) in the electrolyte during the deposition process; otherwise, the precipitation of the nanoparticles occurs and causes the loss of control of the electrochemical codeposition process. Therefore, it is important to present a more fundamental review of the parameters that involve the electrodeposition process of these coatings to obtain a better understanding of the electrochemistry codeposition phenomenon and its consequence on the anticorrosive properties of the composite coatings. Consequently, it will lead to an improvement of the processes for the development of new functional nanocomposite coatings and increase their reliability to prevent corrosion.

\section{Electrochemical codeposition of MMC coatings}

Electroplating or electrodeposition is an electrochemical process that occurs at the interface between a conductive material (electrode) and a conductive solution (electrolyte). As a whole, the process can be explained as the result of applying an electrical potential to the electrochemical system by an external source, and the consequent flow of electric current through the 
electrode-electrolyte interface can be measured (chronoamperometry) [29-31]. On the contrary, an electric current can also be applied, and the generated potential difference is then the measured variable (chronopotentiometry) [32]. In the electrolytic cell of an electrodeposition process, the cathode is generally the working electrode, which will be coated during the procedure, whereas the anode is the counter-electrode. The third electrode is the reference electrode used to monitor the working electrode potential [30,33-35].

The main advantage of this technique is the production of coatings with thickness varying from a few layers up to $40 \mu \mathrm{m}$, relatively free of pores. Compared to the plasma processes (PVD or CVD), it is a less expensive technique and can be conducted at room temperature, normal pressure, and high deposition rate [34,36,37]. In addition, it is economically important because even thin-layer coatings produced by electrodeposition can offer adequate protection to the substrate, avoiding excess of electrodeposited metal $[29,34]$. The most common coatings produced by this process are the metallic ones: nickel, chromium, copper, zinc, tin, brass, silver, and cadmium [31].

The electrodeposition technique also allows the production of coatings composed by a second phase dispersed in a metallic matrix, producing MMC coatings. This second phase can be an organic or inorganic compound or even a metal particle suspended in the solution $[8,34]$. This is the main difference between the usual electrodeposition of metallic ions and the electrodeposition of MMC coatings (electrochemical codeposition): instead of using a pure ionic soluble solution as the electrolyte, particles of nonconductive, semiconductive, and/or conductive nature are suspended in electrolyte solution [11,26,38-40]. Thus, during the codeposition process, both the metal matrix and the particles are deposited on the substrate, producing the MMC coatings [26,38,39].

The greatest challenge faced by those who study the codeposition of nanoparticles in MMC coatings by electrochemical codeposition seems to be the development of a methodology to deposit a sufficient amount of particles to promote the desired improvements in the properties (anticorrosive characteristics, mechanical resistance, etc.) of coatings compared to those obtained with the pure metallic coating. Additionally, it is also necessary to prevent the agglomeration of the particles in the electrolyte solution [23].

A better understanding of the electrocodeposition process is obtained by the knowledge of the process and mechanisms that involve the metal/particle codeposition. Several parameters influence the deposition process, such as applied current density (or potential), concentration of particles in the bath, size of the particles, stirring speed of the suspension, time of previous stirring, solution $\mathrm{pH}$, bath temperature, and electrical nature of the particles. The stability of the suspension of particles to be added to metallic matrix also affects the codeposition process. Although these parameters will be presented in this revision separately, it is important to point out that several of them usually present mutual interactions and these effects can also influence the final results (the amount of codeposited particles, for example) as well as the final properties of the coating. 


\subsection{Parameters affecting the codeposition of particles in metallic matrix}

\subsubsection{Particle concentration in solution}

The particle concentration in the electrolyte may affect the deposition process, changing the ratio metal/particle in the coating and its grain size and causing variations on the coating properties. The incorporation rate per volume of the particles in the deposit is an increasing function of the concentration of particles in the electrolyte suspension $[23,41]$ and is a parameter often used to control the amount of particles in the coating [27,28]. However, as shown in several studies, it is evident that the amount of particles in the deposit does not grow infinitely but reaches a limit value $[5,27,42]$, which depends on the deposition conditions. The concentration of particles in the electrolyte can also result in problems relating to the homogeneity of their suspension, agglomeration, and precipitation [27,28].

Composite coatings of $\mathrm{Zn}-\mathrm{SiO}_{2}$ were produced in the presence of $\mathrm{N}, \mathrm{N}$-dimethyldodecylamine and there was a direct trend in the increase of the amount of incorporated particles up to 100 $\mathrm{g} \mathrm{L}^{-1}$ of silica particles in the solution [6]. Beyond this concentration, however, the increasing incorporation response is oscillating. This behavior was related to the fact that any concentration beyond $100 \mathrm{~g} \mathrm{~L}^{-1}$ of particles might be sufficiently high to induce localized agglomeration, which could lead to uneven distribution of particles in the coatings.

The $\mathrm{TiO}_{2}$ particle concentration $\left(5.0,10.0\right.$, and $\left.15.0 \mathrm{~g} \mathrm{~L}^{-1}\right)$ in the electrolytic bath also influenced the content of these particles in a zinc matrix composite coating [43]. Although the increase of particle concentration in the bath elevated the content of particles in the coatings, concentrations higher than $10.0 \mathrm{~g} \mathrm{~L}^{-1}$ caused a decrease in the codeposited particle content in the metallic matrix. This effect was explained by the agglomeration of particles in the coating due to their poor wettability [43].

The dependence of $\mathrm{TiO}_{2}$ nanoparticles $\left(1.0,1.6,10.0\right.$, and $\left.16.0 \mathrm{~g} \mathrm{~L}^{-1}\right)$ added to different concentrations of $\mathrm{Zn}$ (II) electrolyte $\left(0.5,0.3\right.$, and $\left.0.1 \mathrm{~mol} \mathrm{~L}^{-1}\right)$ on the grain size of the $\mathrm{Zn}$ matrix was also investigated [44]. It was observed that the grain size of the metal matrix decreases with the increase of the nanoparticles added to the bath, which was related to changes in the nucleation and growth processes of zinc crystals due to the presence of these particles. Similar results were obtained for nickel deposition in the presence of $\mathrm{SiC}$ nanoparticles [44] and for copper codeposition with $\mathrm{SiO}_{2}$ nanoparticles [45]. These results are in agreement with the literature, which relates this grain refining effect to the nanoparticle abilities of providing more nucleation sites and, consequently, decreasing the velocity of the crystal growth process [45].

\subsubsection{Particle size in the suspension}

Several works report the influence of the particle size in suspension on the homogeneity of the coating, its microstructure and morphology, and on the particle incorporation in the metal matrix $[37,46,47]$. The number of particles incorporated per area is associated with the selectivity related to the particle size in suspension, as observed for the NiP-SiC coatings, where the amount of $\mathrm{SiC}$ particles in the coating increased due to the decreased size of the $\mathrm{SiC}$ particles in the electrolyte $[27,28]$. However, it is not a consensus in the literature, as there are 
reports showing a reduction in the amount of codeposited particles as their size decreases [5, 6]. In aqueous ionic solution, the particles are easily bonded to each other due to the compression of the diffusion double layer around them, originated by the high ionic strength. Although the stirring of the electrolytic bath may decrease the particle aggregation and favors their codeposition, this effect is more pronounced for particles of micrometric size, as the shear forces on the agglomerates generated by the stirring process decrease with the particle size [5].

The influence of SiC particle size ( $1 \mu \mathrm{m}$ and $45-55 \mathrm{~nm})$ in the microstructure and morphology of the nickel MMC coatings was evaluated [46]. The results showed that, whereas the pure nickel coating presented a pyramidal morphology, the addition of $\mathrm{SiC}$ nano- or microparticles produced a coating with a rough nodular surface. This new morphology was related to the presence of nickel grains surrounding the $\mathrm{SiC}$ particles, forming globular aggregates. It has been argued that the introduction of the ceramic particles disturbed the formation of the metallic matrix and decreased the grain size of the coating [46]. However, no differences were observed concerning the size of the particles.

The effect of microparticle concentration of $\mathrm{SiC}(5$ and $0.3 \mu \mathrm{m})$ in the volumetric percentage of metal deposited on the nickel matrix was evaluated [26], and it was observed that there was an increase in the volumetric percentage of deposited $\mathrm{SiC}$ particles as their concentration in the bath increased, independent of the particle size. However, the greatest volumetric percentage of codeposited $\mathrm{SiC}$ particles was obtained using $5 \mu \mathrm{m}$ particles, whereas the lowest percentage was deposited using $0.3 \mu \mathrm{m}$ particles. It was pointed out that a direct comparison of the volumetric percentage of codeposited particles with different sizes may lead to a misunderstanding because of the differences in the particle density on the composite coating [26].

The effect of SiC particle size (1.2, 8.0, 14.0, and $20.0 \mu \mathrm{m})$ on nickel composite coatings was investigated by Kim and Yoo [48], and it was verified that an increase in the size of the particle (until $14 \mu \mathrm{m}$ ) added to the electrolytic bath induced an increase in the content of the particles in coatings. This fact was explained by the adsorption of $\mathrm{Ni}^{2+}$ ions on the particles, resulting in a strong Coulomb force and an increase of the $\mathrm{SiC}$ particles codeposited. Above $14 \mu \mathrm{m}$, however, the particles presented a sedimentation tendency due to their weight, which decreased the suspension stability and the content of SiC particles codeposited in the metallic matrix [48].

\subsubsection{Current density}

Besides the particle concentration of the suspension, the applied current density is certainly the parameter most studied by several authors $[37,38,47,49]$ and there are evidences concerning its effect on the particle incorporation. The literature [5] reports that the particle incorporation in the coating is a function of the current density and that this effect can be divided in four current density regions. Initially, there is a region where the particle incorporation increases rapidly reaching a maximum followed by the second region where a marked decrease in the process occurs. Then, a third region takes place, where the process is fairly constant, followed by another fall in the particle content in the current density region where the metal reduction is limited by mass transfer. It seems that an optimum range of current density is necessary to 
favor the codeposition of the particles. This range, however, depends on the studied particle and on other deposition parameters, such as bath composition or stirring.

For example, the greatest amount of $\alpha-\mathrm{Al}_{2} \mathrm{O}_{3}$ nanoparticles was incorporated to a copper matrix at low current density values (between 1 and $2 \mathrm{~A} \mathrm{dm}^{-2}$ ), whereas, outside this range, the content of particles in the coating significantly decreased [11]. This dependence between the content of nanoparticles in the coating and the current density is explained by the mechanism by which the particles are captured. The increase in the particle content in the coatings occurs in the region where the reduction of the metallic ions is under charge transfer control and where the reduction of adsorbed cations on alumina is the determining step of the deposition rate. As the reduction of metal ions occurs under diffusion control at current densities higher than $2 \mathrm{~A}$ $\mathrm{dm}^{-2}$ (the hydrodynamic conditions are not mentioned), the codeposition of alumina particles gradually decreases with increasing current density [11].

It was also observed that increasing current density caused a decrease in the initial rate of incorporation of $\mathrm{SiO}_{2}$ particles in the zinc matrix; however, at current densities approximately $30 \mathrm{~A} \mathrm{dm}^{-2}$, an increase in $\mathrm{SiO}_{2}$ deposition rate was noted, mainly for the particles with the highest size $(2 \mu \mathrm{m})$ [6]. Moreover, the regions in which the particle incorporation increased or decreased markedly with current density were sensitive to particle size. The authors suggested that the deposition process was controlled by mass transfer until the maximum value of current density, where the codeposition process was favored. Otherwise, the process was controlled by the particle adsorption on the substrate, and a further increase in current density resulted in the rapid deposition of the metallic matrix and less particles were included in the coating [6]. Similar results were obtained for composite coatings of Ni-Co alloy matrix containing SiC particles with $50 \mathrm{~nm}$ of diameter [37].

The literature reports that this relationship between the current density and the amount of incorporated particles also influences the microstructure of the produced MMC coatings $[47,49]$. For example, the $\mathrm{Ni} / \mathrm{Al}_{2} \mathrm{O}_{3}$ coatings produced at current density values of $10 \mathrm{~A} \mathrm{dm}^{-2}$ from an acid sulfamate-based bath $(\mathrm{pH} 4.3)$ presented a more refined microstructure than the coatings produced at lower current density values [50]. It is an important feature, as the microstructure of the coatings can be consequently related to their corrosion resistance.

In addition, the mode of applied current [continuous (DC) or pulsed current (PC)] may also influence the microstructure and corrosion properties of the MMC coatings. Composite coatings of copper matrix and $\beta$-SiC particles were produced under DC and PC conditions [51]. The coatings containing $\beta$-SiC particles deposited under DC conditions showed grains more refined than those observed from the copper coating. However, this coating presented voids between the incorporated particles and the metal matrix, which influenced the anticorrosive properties of the composite coating, as evidenced by the corrosion tests performed in $0.5 \mathrm{~mol}$ $\mathrm{L}^{-1} \mathrm{Na}_{2} \mathrm{SO}_{4}$ solution ( $\mathrm{pH}$ 2). These coatings showed less resistance to both uniform and localized corrosion compared to the pure metal coating. On the contrary, the coatings produced using PC presented a more compact microstructure and, as a consequence, showed elevated resistance to uniform corrosion, similar to pure copper coating and greater than the coatings produced under DC [51]. 
Another example is the study that evaluated the influence of DC, PC, and pulsed reverse current (PRC) on the content of particles incorporated to a nickel metallic matrix [36]. The particles used were $\mathrm{Al}_{2} \mathrm{O}_{3}(150 \mathrm{~nm}), \mathrm{SiC}(30-60 \mathrm{~nm})$, and $\mathrm{ZrO}_{2}(200 \mathrm{~nm})$, and for all systems studied, the particle content in the composite coatings increased when the coatings were produced by PC and PRC; the amount of particles obtained using DC was always lower. The periodic switching of current (between positive values and zero for PC and between positive and negative values for PRC) permitted the discharging of the double layer, allowing a higher access of the particles (with adsorbed ions on their surfaces) toward the cathode. The ions adsorbed on the particles were subsequently reduced on the cathode surface causing a capture of the reinforcement material during coating growth.

\subsubsection{Stirring speed}

The electrolyte stirring speed plays an important role in any electrodeposition process, as it favors the transport of metallic ions to the electrode, increasing the deposition rate [52]. In the electrochemical codeposition process of MMC coatings, however, the influence of this parameter is even greater because it affects the homogeneous dispersion of the particle in the suspension and controls the frequency of collision between the particles and the cathode. Furthermore, the stirring speed of the electrolyte influences the mechanism of particle deposition onto the cathode surface as well as the time they will remain adsorbed $[27,41]$.

In general, if the stirring speed of the bath is too slow, it prevents the complete dispersion of the particles, and their sedimentation during the deposition process cannot be avoided. On the contrary, if the stirring speed is too high, the particles do not have enough time to be adsorbed to the substrate surface, resulting in a low amount of particle incorporation [5]. Moreover, under excessive high stirring speed values, the amount of particles transported to the cathode is too large to be trapped by the matrix growth, which causes the collision of the free particles (those particles that have not been adsorbed or incorporated yet) with other particles that are reaching to the cathode. These collisions result in a decrease in the incorporation rate [5].

Therefore, this parameter should be optimized to avoid both particle sedimentation and the removal of the particles, which are already in the adsorption phase on the cathode. Nonetheless, the stirring speed range that must be used to achieve the MMC coatings is not a consensus in the literature and it seems to depend on the kind of particle, the metallic ions and bath composition used, as well as the cell configuration and volume [30,47,53,54].

The incorporation of particle $\alpha-\mathrm{Al}_{2} \mathrm{O}_{3}$ in a $\mathrm{Co}-\mathrm{Ni}$ matrix from a Ni(II)/Co(II) sulfamate acid bath containing the suspended particle was studied, under magnetic stirring varying between 40 and $160 \mathrm{rpm}$ [12]. The volume fraction of $\mathrm{Al}_{2} \mathrm{O}_{3}$ particles in the composite coating $\left(\mathrm{V}_{\mathrm{p}}\right)$ increased with stirring speed and reached a maximum value (approximately $8 \mathrm{vol} \%$ ) at $100 \mathrm{rpm}$, decreasing with further increased stirring. The authors suggested that the codeposition of $\mathrm{Al}_{2} \mathrm{O}_{3}$ particles in the Co-Ni alloy was apparently controlled by the particle transfer up to 100 $\mathrm{rpm}$. A further increase the stirring speed could have displaced the particles spontaneously adsorbed onto the surface of the cathode, causing a reduction in the $\mathrm{V}_{\mathrm{p}}$ values of the codeposited particles. 
Another study [47] showed that there is a maximum value of particles of $\mathrm{CeO}_{2}$ (between 15 and $20 \mathrm{~nm}$ ) incorporated to nickel matrix when the stirring speed was varied (100, 250, 350, 450 , and $550 \mathrm{rpm}$ ). The highest quantity of particles in the matrix was obtained at $450 \mathrm{rpm}$; above this value of stirring speed, the content of $\mathrm{CeO}_{2}$ decreases. This phenomenon was explained by the collision of particles on the cathode under high values of stirring speed. Moreover, the increase of stirring speed also enhanced the turbulence in the flux suspension, which could have removed the weakly adsorbed particles from the cathode surface [47]. Similar results were obtained by other research groups $[15,49,54]$ for different nickel composite coatings.

\subsubsection{Solution temperature}

The solution temperature affects several physical properties of the suspension (such as the viscosity and the sedimentation rate) and influences the reduction kinetics of the free and adsorbed cations as well as the possible adsorption of particles on the cathode [27]. Although there are few works in the literature studying the effects of this parameter in the electrochemical codeposition process, these works show the relationship between the solution temperature and the increase of codeposited particles in metallic matrix or the morphology of the coating. Thus, this parameter is still scarcely explored and understood.

The temperature of $50^{\circ} \mathrm{C}$ was considered the most beneficial one for the incorporation of alumina particles in Co-Ni matrix from an acidic $\mathrm{Ni}(\mathrm{II}) / \mathrm{Co}(\mathrm{II})$ sulfamate bath instead of $60^{\circ} \mathrm{C}$ [12]. For the codeposition of alumina particles in $\mathrm{Cr}$ matrix from a sulfate bath containing a rare earth element (not mentioned), the best temperature range for particle incorporation was from $30^{\circ} \mathrm{C}$ to $40^{\circ} \mathrm{C}$. When the temperature was below $30^{\circ} \mathrm{C}$, the composite coating was rough, whereas, when it was above $40^{\circ} \mathrm{C}$, the composite coating decreased; beyond $55^{\circ} \mathrm{C}$, there was no $\mathrm{Al}_{2} \mathrm{O}_{3}$ codeposited with $\mathrm{Cr}$ [55].

Research works carried out for Zn-SiC composite coatings [56] showed that the increase of solution temperature $\left(33-45^{\circ} \mathrm{C}\right)$ caused a significant reduction of particle content in the coating. The authors considered that the increase in the solution temperature favored the electroactive species reduction, while it did not increase the codeposition of the $\mathrm{SiC}$ particles. Kim and Yoo [48] verified the same behavior for Ni-SiC composite coatings.

It is important to mention that the overall result concerning the temperature variation on the codeposition process for producing MMC coatings is difficult to predict, as the parameter most affected by the solution temperature is not generally identified in the usual used deposition mechanisms $[12,27]$.

\subsubsection{Composition of the electrolyte bath}

The production of MMC coatings by electrodeposition is highly influenced by the composition of the electrolytic bath, as the presence of complexants, surfactants, or dispersant agents may affect the metallic ion deposition process, the suspension stability, and the particle incorporation in the coating. Moreover, the acidity of the bath $(\mathrm{pH})$ as well as the concentration of the baths components may also influence the particle dispersion and the codeposition of the 
species. Therefore, bath composition is one of the most studied topics in the production of MMC coatings by this technique, and the properties of the produced coatings obtained from different baths may certainly vary.

The electrolyte composition and the solution $\mathrm{pH}$ directly influence the $\zeta$ potential measurements, which is the main variable related to the stability of solid particle dispersions in aqueous solution [57]. Charged surface particles form more stable suspensions because the mutual repulsion between the particles increases, decreasing their agglomeration $[27,45,58]$. Therefore, the increase in the particle charge (in modulus) will result in a higher (also in modulus) $\zeta$ potential and in a more stable suspension.

Surfactants agents are generally used to promote a better dispersion of suspensions because they reduce the surface energy of the particles, deeply influencing the codeposition process. The surfactants or surface-active agents are characterized by having two distinct regions on the same molecule: a hydrophilic polar region and a hydrophobic nonpolar region. These compounds have activity at the surface interfaces between two phases, such as water-air and oil-water, and the solid-liquid interface [46]. For experimental evaluation, these additives apparently act in two ways: by modifying the properties of the particle surface and stabilizing the suspension and/or by affecting the reduction of metal ions during electrodeposition [4].

Nanoparticles of $\mathrm{Al}_{2} \mathrm{O}_{3}$ suspended in a $0.001 \mathrm{~mol} \mathrm{~L}^{-1} \mathrm{KCl}$ solution presented $\zeta$ potential values almost constant and positive for a $\mathrm{pH}$ range between 2 and 6 . However, at higher $\mathrm{pH}$ values, the $\zeta$ potential shifted to less positive values until it reached the isoelectric point (IEP), where the particles had no charge and then precipitated ( $\mathrm{pH}$ 9.2) [59]. On the contrary, in the presence of nickel sulfamate bath, the $\zeta$ potential of these particles was positive in the entire $\mathrm{pH}$ range between 2 and 12 probably due to the adsorption of nickel cations on the alumina particles; in the case of pyrophosphate electrolytes, the $\zeta$ potential remained negative, which was related to the adsorbed pyrophosphate anion. Both in the presence of sulfamate and the pyrophosphate baths, it was not possible to determine the IEP in the $\mathrm{pH}$ range studied. Thus, the authors concluded that alumina particles take on negative charges in alkaline baths, whereas, in acidic electrolytes, they assume positive charges.

The sign of the charges on the particle surface will also influence the deposition process, although both positive and negative charges are considered to improve the incorporation of the particles. For example, the codeposition of $\alpha-\mathrm{Al}_{2} \mathrm{O}_{3}$ particles in a Co-Ni matrix from a $\mathrm{Ni}(\mathrm{II}) /$ $\mathrm{Co}(\mathrm{II})$ acid sulfamate bath was found to be enhanced by the presence of $\mathrm{Co}(\mathrm{II})$ ions adsorbed on the particle surface, which charged them positively [12]. In opposition, the presence of negatively charged alumina particles (due to the presence of citrate or pyrophosphate anions adsorbed on them) also increased the codeposition of $\mathrm{Al}_{2} \mathrm{O}_{3}$ particles on $\mathrm{Cu}$ matrix [10]. In this last case, the negatively charged particles were codeposited in the metallic matrix in higher amounts than the positively charged ones. A possible explanation is that the negatively charged particles would be attracted by the double layer of the substrate that was charged with excessive positive charge [probably $\mathrm{Cu}(\mathrm{II})$ ions] under the conditions of the electrodeposition experiment [10]. Although these arguments do not imply that the electrodeposition is completely governed by electrostatic forces, the proposed mechanism helps streamline the experimental results for the present system [10,59]. 
However, each system can produce unique responses to the addition of surfactants or changes in the bath composition. The addition of N,N-dimethyldodecylamine in $\mathrm{Zn}$ (II) baths containing $\mathrm{SiO}_{2}$ particles $(20 \mathrm{~nm})$ has not caused a significant increase in the incorporation rate of these particles, as similar amounts (approximately $5 \mathrm{wt} \%$ ) were obtained in both the presence and absence of the amine. Nonetheless, for particles with size of $2 \mu \mathrm{m}$, there was an increase in the incorporation rate with the addition of the surfactant and the $\mathrm{SiO}_{2}$ content on the coating was $14 \mathrm{wt} \%$. Therefore, there was a joint effect of the particle size and the dispersion effect caused by the presence of the surfactant in the bath [6].

The effects of adding cetyltrimethylammonium bromide (CTAB), a cationic surfactant, at concentrations of $10^{-5}$ to $10^{-3} \mathrm{~mol} \mathrm{~L}^{-1}$ on the codeposition process of $\mathrm{SiO}_{2}$ particles in a copper matrix was also investigated [45]. It was found that the $\zeta$ potential of the suspension in the absence of the additive was negative in the whole $\mathrm{pH}$ range studied (3-9). It was assumed that, at high $\mathrm{pH}$ values, there were hydroxyl groups (negative ions) on the surface of silica particles.

The introduction of small concentrations of CTAB in the $\mathrm{CuSO}_{4}$ solution induced changes in the $\zeta$ potential of the nanoparticles, which assumed positive values for all CTAB concentration ranges. A reasonable explanation for this behavior would be the easy adsorption of the cationic surfactant on the surface of silica nanoparticles because of the positive charge in the polar part of CTAB molecules. These molecules reacted with the hydroxyl groups on the silica surface, decreasing the surface energy of the nanoparticles, improving the state of dispersion of $\mathrm{SiO}_{2}$ particles [45]. In addition, the steric effect between the $\mathrm{SiO}_{2}$ nanoparticles became higher as the CTAB chain was grafted on their surfaces.

However, it is very difficult to correlate the results obtained in the $\zeta$ potential measurement, which is generally carried out at low electrolyte ion concentrations (low ionic strength), with the behavior of a particle in an electrolyte used for electrodeposition (i.e., high ionic strength). Therefore, it is not easy to verify the dispersion influence of the surfactants in the electrochemical codeposition process [10,48]. Moreover, the addition of surfactants should be carefully used, because an excessive increase in their concentration may create a large repulsion force between the surfactant layer next to the cathode and the surface of the particle. At high concentrations, the surfactants form micelles in solution and the uniform dispersion of previously formed nanoparticles is interrupted, promoting their agglomeration and reducing their incorporation in coatings [7].

The concentration of the metallic ion in the electrolyte also affects the properties of the MMC coatings produced by electrodeposition. The grain size of $\mathrm{Zn}$ metallic matrix was substantially independent of the concentration of $\mathrm{TiO}_{2}$ particles for concentrated ionic solutions. However, for more dilute solutions $\left(0.1 \mathrm{~mol} \mathrm{~L}^{-1}\right)$, it was observed that the grain size decreased with the increase of the nanoparticle amount. This was explained mainly by changes in the growth and nucleation of zinc crystals due to the concentration of the metallic ions and the presence of semiconductor particles. For dilute solutions, the evolution of hydrogen and the presence of particles should promote a detrimental effect on the crystal growth, leading to smaller grains in the zinc matrix [44]. 


\subsubsection{Electrical nature of the particles}

The electrical nature of the particles used to produce the MMC coatings has drawn the attention of very few researchers. However, it is important to have information about how the codeposition of inert, semiconductor, or conductive particles influence the overall process [11]. Apparently, conductive particles are readily incorporated into the metallic coatings, although dendritic, uneven, and very rough deposits are obtained. On the contrary, the codeposition of insulating particles is very slow, producing relatively homogeneous and smooth deposits [17]. This fact can be used for the production of composite coatings with different applications: the smooth ones could be applied for mechanical and/or anticorrosion uses, whereas those with very high specific surface area and using conductive particles with some catalytic properties entrapped in the coatings could act as catalysts in some chemical or electrochemical processes [60].

The codeposition of inert $\left(\alpha-\mathrm{Al}_{2} \mathrm{O}_{3}\right)$, semiconductive ( $\left.\mathrm{SiC}, \mathrm{MoS}_{2}\right)$, and conductive (graphite) particles in a copper metallic matrix was studied and it was found that the distribution of inert particles in the coating was uniform and an acceptable surface quality (no roughness) was obtained even at high current density values [11]. When semiconductive and, especially, conductive particles were incorporated to the copper matrix, however, spongy and irregular coatings were produced, showing high surface roughness mainly at high values of current density. Therefore, the increase in the conductivity of the particles changed the specific surface area and increased the roughness of the coating.

These results confirm that the codeposition process as well as the morphology and microstructure of the coatings are affected by the electrical nature of the particles. The presence of more conductive particles in suspension, such as graphite for example, may act as a suspension electrode in the process, as shown by Iwakura [60]. Graphite particles in contact with the cathode were polarized and the deposition of copper could have occurred onto the particles as well as onto the cathode. Such codeposition mechanism could explain the unsuitable deposit structures and the coppering of graphite particles, as observed by Stankovic and Gojo [11]. However, to the best of our knowledge, this mechanism has not been validated yet.

\subsubsection{Previous stirring time of the particles in the solution}

The effects of the period of time the particles are maintained suspended in the solution before the electrochemical codeposition process occurs (the previous stirring time) on the characteristics of the codeposited coatings are not usually investigated in the literature. However, it is possible to verify that composite coatings are produced after previous stirring time values ranging from $30 \mathrm{~min}$ to $24 \mathrm{~h}$, without any explanation about this choice even if the same kind of particle was used $[18,26,38,51]$. The suspension is generally stirred to enhance the dispersion of the particles and promote their codeposition $[11,18,26,34,38,51,61,66]$. Therefore, the time used to keep the nanoparticles suspended must be directly related to the codeposition process.

An introductory study concerning the effect of the previous stirring time was performed to produce copper MMC coatings reinforced with micrometric $\gamma-\mathrm{Al}_{2} \mathrm{O}_{3}$ onto steel substrate (AISI 1020) [61]. The coatings were produced by chronoamperometry, using a pyrophosphate-based 
bath, under constant stirring speed $(800 \mathrm{rpm})$ and using different values of previous stirring time (ranging from 1 to $5 \mathrm{~h}$ ). Figures 1 to 3 present the surface morphology of the coatings obtained under these conditions.

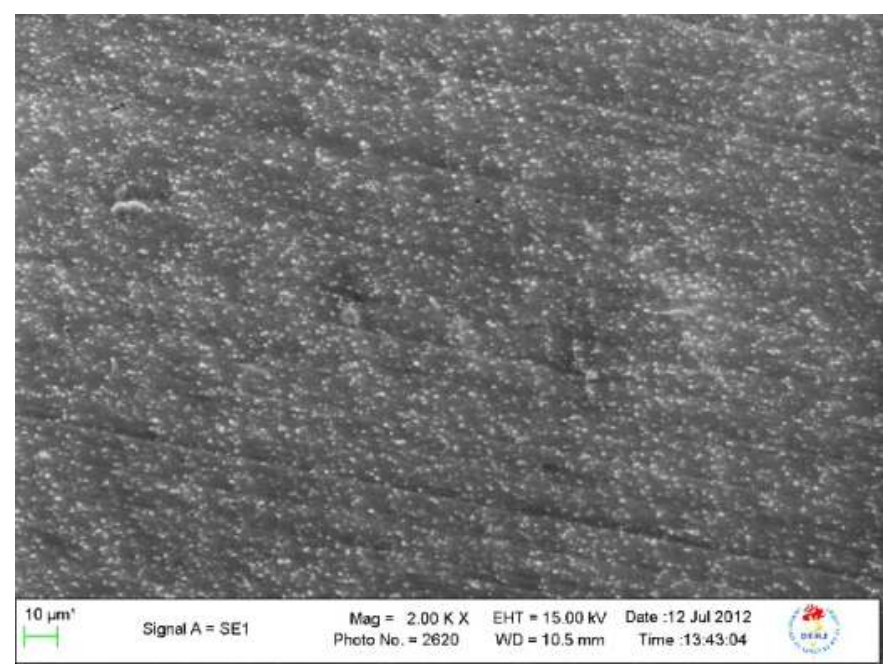

Figure 1. Surface morphology of $\mathrm{Cu} / \gamma-\mathrm{Al}_{2} \mathrm{O}_{3}$ coatings produced at $-1.20 \mathrm{~V}_{\text {SSE }}$ from pyrophosphate bath previously stirred for $1 \mathrm{~h}$ at $800 \mathrm{rpm}$ [61].

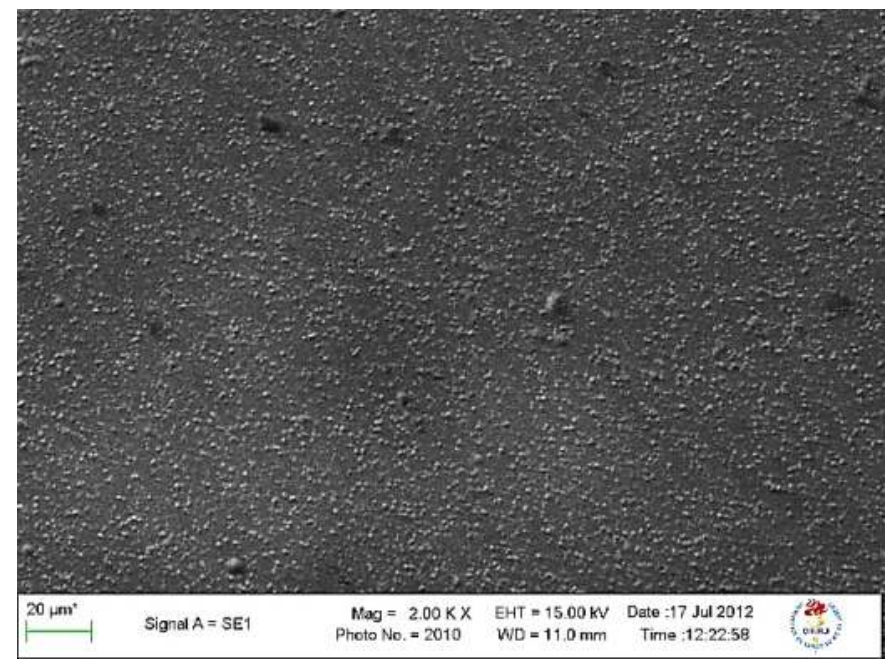

Figure 2. Surface morphology of $\mathrm{Cu} / \gamma-\mathrm{Al}_{2} \mathrm{O}_{3}$ coatings produced at $-1.20 \mathrm{~V}_{\text {SSE }}$ from pyrophosphate bath previously stirred for $3 \mathrm{~h}$ at $800 \mathrm{rpm}$ [61]. 


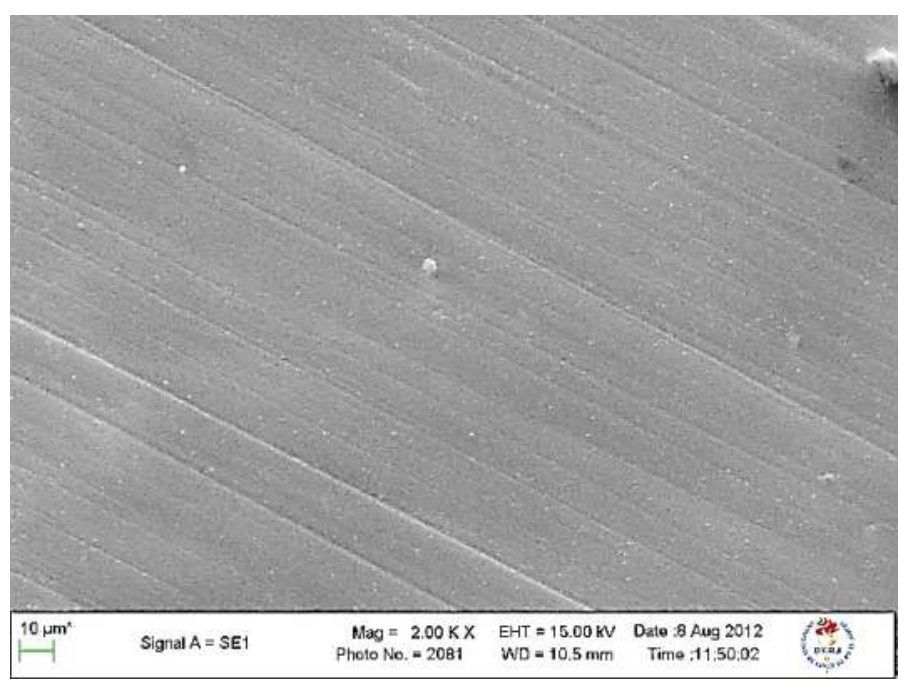

Figure 3. Surface morphology of $\mathrm{Cu} / \gamma-\mathrm{Al}_{2} \mathrm{O}_{3}$ coatings produced at $-1.20 \mathrm{~V}_{\text {SSE }}$ from pyrophosphate bath previously stirred for $5 \mathrm{~h}$ at $800 \mathrm{rpm}[61]$.

It is possible to observe that the previous stirring time influenced the dispersion of the $\gamma$ $\mathrm{Al}_{2} \mathrm{O}_{3}$ particles in the copper matrix. The particle agglomerates in the coating produced after $1 \mathrm{~h}$ of previous stirring (Figure 1) seem to decrease when the previous stirring time increased to $3 \mathrm{~h}$ (Figure 2). After $5 \mathrm{~h}$ of previous stirring, the particles seem to be homogeneously dispersed in the copper matrix (Figure 3). These results indicated that this parameter may have a fundamental role to produce coatings presenting dispersed second-phase particles and consequently enhanced mechanical and anticorrosive resistances.

Additionally, the coatings produced after 1, 3, and $5 \mathrm{~h}$ of stirring (Figures 1-3) were chemically analyzed, producing $9.74 \mathrm{wt} \% \mathrm{Al}_{2} \mathrm{O}_{3}, 16.7 \mathrm{wt} \% \mathrm{Al}_{2} \mathrm{O}_{3}$, and $9.98 \mathrm{wt} \% \mathrm{Al}_{2} \mathrm{O}_{3}$, respectively [61]. There is an increase in the $\mathrm{Al}_{2} \mathrm{O}_{3}$ content from the experiment conducted after 1 to $3 \mathrm{~h}$ of stirring and a small decrease when the previous stirring time increases to $5 \mathrm{~h}$. This result indicates that it must be an optimum time to stir the suspension before electrodeposition be performed to produce coatings with completely dispersed particles and presenting high amount of particulate material incorporated into the metallic matrix. These initial results suggest that the previous stirring time must be carefully studied to produce high-quality composite coatings.

\subsection{Electrochemical codeposition mechanisms}

The electrochemical codeposition process has been under investigation for several years. Many works have demonstrated the influence of the cations and anions present in the electrolyte and the effects of organic and inorganic additives in the incorporation of the particulate material on the composite coatings. Moreover, as the particulate material should be kept suspended in solution throughout the deposition process, the stirring process is also important for obtaining the MMC coatings [62-67]. Thus, some studies concerning the codeposition mechanism have 
been carried out trying to propose models that could explain the influence of the deposition parameters on the codeposition phenomenon of inert particles in metallic matrix during the electroplating of a cathodic composite coating [6,8,11,23,24,62-64].

The main problem faced by the authors who proposed such mechanisms was the physical explanation concerning the direct influence of deposition parameters, such as current density, particle concentration in the bath, stirring speed of the suspension, solution $\mathrm{pH}$, and temperature, for example, on the codeposition phenomenon $[38,47,48]$. It is a very hard task, and only two models, regarding the codeposition of inert particles, are well accepted $[63,64]$.

\subsubsection{Two-step adsorption codeposition model}

Earlier codeposition mechanisms [68-70] suggested that two different phenomena should be taken into account to explain the deposition of inert particles: electrophoresis and adsorption. Although both possibilities can be supported by good arguments, there are also effective contradictions.

An electrophoretic effect could explain the observed effect of the current density on the coating. However, there are some difficulties to explain the effects of other parameters, such as, for example, the nonlinear dependence on the particle concentration. Two main objections can be made against the possibility of an electrophoresis effect controlling the codeposition of these particles. First, it should consider the fact that electroplating baths are high ionic strength media, thus presenting no electrophoretic effect. Second, as the mechanism considers only the inert particles (uncharged), they should not respond to a negatively charged electrode. On the contrary, it would be a mistake to consider only a mechanism based on particulate adsorption, because a simple adsorption mechanism could not give a satisfactory explanation for the effect of the current density on the coating [63,71].

Guglielmi [63] developed a hypothesis that used some concepts of the two previously described mechanisms, although the author tried to eliminate the earlier mentioned contradictions. The proposed model was based on two consecutive adsorption steps. The first step is substantially of physical nature and leads to the production of a layer of weakly adsorbed particles on the cathode, with a very high coverage; the second step was dependent on an auxiliary electric field, and thus substantially of electrochemical character, producing a strong adsorption of the particles on the electrode. The strongly adsorbed particles are then progressively covered by the metal growth and become incorporated to the coating.

This model presents a good physical meaning. It is possible to infer that, in the first step, the inert particles are surrounded by a thin layer of adsorbed ions and solvent molecules; these charged particles can then interact with the electrode. In the second step, the existing electric field at the interface between the substrate and the inert particles (charged by the electrolyte components) contributes to produce a strong adsorption field. There is a clear analogy between the two-step adsorption postulated for particles and the adsorption of ions on the external and internal Helmholtz plans, respectively [63].

Figure 1 shows a generic representation of the model proposed by Guglielmi [63]. It can be shown that the postulated mechanism is not affected by the above-mentioned contradictions 
and makes it possible to justify the influence of both the current density and the nonlinear particle concentration on the deposition process.

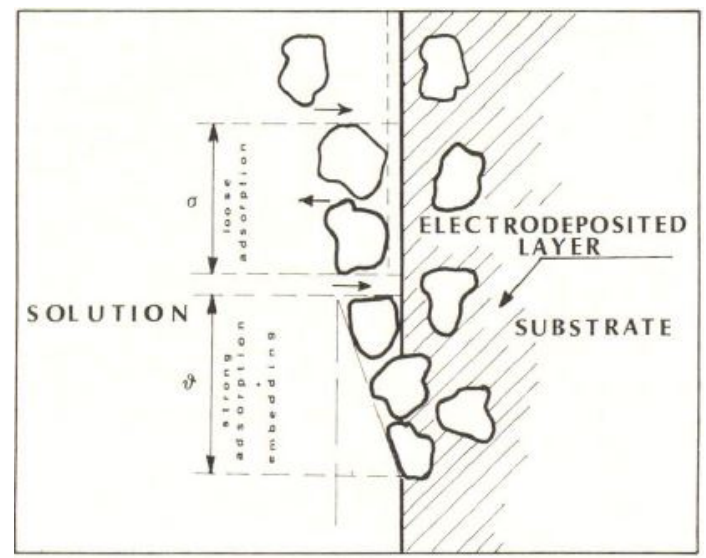

Figure 4. Schematic representation of the different stages of the electrochemical codeposition, as suggested by Gugliel$\mathrm{mi}[63]$.

The proposed model was then validated by a mathematic treatment and submitted to an experimental evaluation [63]. It used a nickel sulfamate bath containing $\mathrm{TiO}_{2}$ particles $(1 \mu \mathrm{m})$ and $\mathrm{SiC}(2 \mu \mathrm{m})$. It is important to mention, however, that none of these particles present inert electrical nature. The deposits were obtained at current densities of 2, 5, and $10 \mathrm{~A} \mathrm{dm}^{-2}$, and the analysis of particle concentration in the coating was performed by gravimetric methods. The experimental data agreed with the codeposition proposed mechanism based on a twostep adsorption process. It was found that the concentration of the weakly adsorbed particles was twice the concentration of the particulate material in the suspension, thus justifying the premature saturation of the surface that was indicated by the first step model. However, in highly diluted suspensions, a fraction of the particles weakly adsorbed on the electrode was removed. The lowest concentration of the strongly adsorbed particles, as suggested by the second step model, was related to the reduction of the ions, which was relatively slow, compared to the rate of adsorption of the first step. The deposition of inert particles depended on the studied deposition parameters (current density and particle concentration in the bath). This model also explains the strong dependence on the particle concentration in the solution observed during codeposition, because the behavior of the particles strictly depended on the structure of molecules and ion layers adsorbed on the particle surface and indirectly on the electrolyte composition [62].

\subsubsection{Five-step codeposition model for inert particles [63]}

The groundings of Guglielmi's model [63] proved the importance of the mathematical treatment of the electrolytic bath in the codeposition process. However, some derivations and 
unexplained questions have arisen, and the generality of the model was questioned. Considering only current density and particle concentration in the solution as the single parameters that control the process, this model ignored other important process parameters, such as hydrodynamics and the effect of bath constituents and its electrolytic conditions, such as $\mathrm{pH}$ and bath temperature. Therefore, the Guglielmi's model [62] was not considered able to predict how these other parameters affect the electrolytic codeposition of the particles [64].

The electrolytic codeposition mechanism of inert metal particles, proposed by Celis et al. [64], was based on two fundamental assumptions:

1. A layer of adsorbed ionic species is created around the inert particles when the particles are added to the solution or during pretreatment of the particles in ionic solutions, and

2. The reduction of some of these adsorbed ionic species is required for embedding particles in the metal matrix.

Thus, the incorporation of inert particles in the metal matrix proposed by Celis et al. [64] follows the next five stages and is schematically shown in Figure 5.

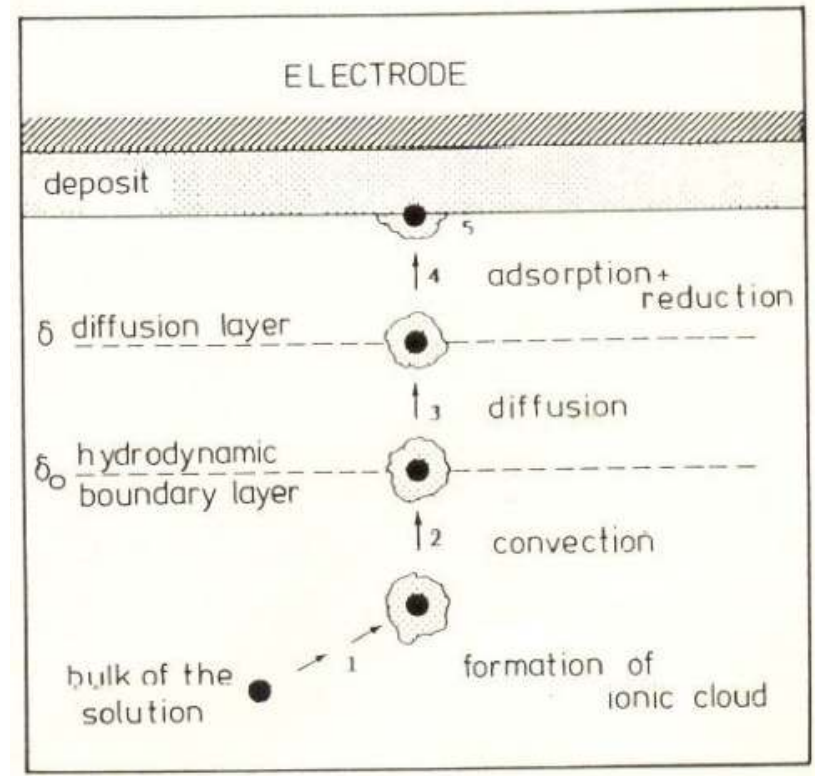

Figure 5. Model proposed by Celis et al. [64] to describe the incorporation of a particular material in composite coatings.

1. Adsorption of ions and molecules occurs on the surface of the particles suspended in the electrolyte.

2. The particles are transferred to the hydrodynamic boundary by convection. 
3. The particles diffuse through the cathode diffusion layer.

4. The particles adsorb on the surface of the deposit.

5. The particles are trapped into the coating by the reduction of the ions adsorbed on their surface and the growth of the metallic matrix begins.

The model was constructed assuming the steady-state conditions, so that there are no variations in concentration, pressure, temperature, or overpotentials during the process. It was also assumed that the cathode surface could be uniformly accessible by both the ionic solution and the inert particles. Finally, it was considered that a homogeneous suspension of particles in the coating solution was maintained [63]. In the diffusion layer, the ions move toward the cathode and carry the inert particles with them; simultaneously, a certain amount of ions is adsorbed. Once on the electrode surface, the ions are reduced to meet the demands of the reduction process [64].

This model showed that the codeposition process depends on many variables, although the most important are the current density and the overpotential. These two parameters influenced all the others, except those related to the particle (the nature of the particle, its weight, and its quantity in the suspension), the hydrodynamic conditions that influence the content of incorporated particles, and the probability that the codeposition occurs [64].

However, it is necessary to consider that particles of different nature can be used and differentiate the codeposition process of inert and conductive particles. Conductive particles are generally deposited in a greater amount than the inert particles and tend to cause dendrite growth of the metal matrix [5,11,44,45]. Neither the model proposed by Celis et al. [64] nor that suggested by Guglielmi [62] included the electrical nature of the particles as an important and influent parameter to be considered in their models. However, if all parameters are considered constant, there is a high probability of codeposition of conductive particles using the same mechanism proposed by Celis et al. [64].

Similar to what has been described for the first model, the present model was also validated by a mathematic treatment and submitted to an experimental evaluation [51]. In this case, it used $\mathrm{CuSO}_{4}$ or $\mathrm{KAu}(\mathrm{CN})_{2}$ solutions ( $\mathrm{pH} 0.3$ and 4.0, respectively), in which particles of $\gamma$ $\mathrm{Al}_{2} \mathrm{O}_{3}\left(0.05 \mu \mathrm{m} ; 20.0 \mathrm{~g} \mathrm{~L}^{-1}\right)$ were added. The conditions of the experiments are shown in Table 2. The model proved to be valid for the codeposition of composite $\mathrm{Cu} / \gamma-\mathrm{Al}_{2} \mathrm{O}_{3}$ coatings from sulfate acid baths and for $\mathrm{Au} / \gamma-\mathrm{Al}_{2} \mathrm{O}_{3}$ coatings from cyanide acid baths.

\begin{tabular}{lcc}
\hline \multicolumn{1}{c}{ Studied parameters } & Cu matrix & Au matrix \\
\hline $\mathrm{pH}$ & 0.3 & 4.00 \\
\hline Temperature $\left({ }^{\circ} \mathrm{C}\right)$ & 20.0 & 40.00 \\
\hline Stirring speed $(\mathrm{rpm})$ & 400 & 600 \\
\hline Current density $\left(\mathrm{A} \mathrm{dm}^{-2}\right)$ & $2.0 ; 10.0$ & $0.35 ; 4.25$ \\
\hline
\end{tabular}

Table 2. Conditions used to produce copper and gold matrix composite coatings containing $\gamma-\mathrm{Al}_{2} \mathrm{O}_{3}$ particles [64]. 


\section{Functional composite coatings with improved mechanical properties}

It is well known that the mechanical characteristics of coating materials produced by electrodeposition are related to their microstructure, concerning the effects of grains and grain boundaries and also the preferred orientation of the deposits, which are dependent on the electroplating parameters [72-74]. The presence of particles in the electrolytic bath that are incorporated to the final electrodeposited coating will also contribute to changes in the coating microstructure and can create new mechanical features for these coatings.

There are several works in the literature in which MMC functional coatings are produced to improve the mechanical properties of the substrate. Some of them are presented here $[37,38,40,47,75]$ as an example, because this item alone could be the topic of another review chapter. The generally studied electrodeposition parameters, such as stirring speed or current density, are still mentioned $[47,75]$. For example, the electrolytic bath stirring speed affected the hardness of nickel matrix composite coatings produced with the addition of particles of $\mathrm{CeO}_{2}$ (size between 15 and $20 \mathrm{~nm}$ ) in the electrolytic bath [47]. The hardness of the MMC coatings increased with the stirring speed, reaching its maximum value $(760 \pm 80 \mathrm{HV})$ at 450 $\mathrm{rpm}$. Above this stirring speed value, however, there was a reduction in the coating hardness, which would be associated with the agglomeration of the particles of $\mathrm{CeO}_{2}$ in metallic matrix.

Most of the works found in the literature, however, are related to the mechanical effects concerning the presence of the particle in the coating, the amount of these particles, and their size [38,75-78]. As the MMC coatings reinforced by particles with larger sizes ( $\mu \mathrm{m}$ or higher) are susceptible to the formation of defects during mechanical loading, resulting in a premature failure of the composite coatings, it is expected that coatings containing nanorange particles present superior mechanical properties. Therefore, nanocomposite coatings could overcome some limitations, such as poor ductility and elongation, poor wear resistance, and reduced fracture toughness presented by some MMC coatings [77,78].

Nanohardness evaluations were performed by applying normal and lateral force (friction) on nickel metallic matrix reinforced (or not) with $\mathrm{SiC}$ particles measuring $10 \mathrm{~nm}, 50 \mathrm{~nm}$, or $5 \mu \mathrm{m}$ [38]. It was observed that the addition of the particles in the composite coating decreased the penetration of the Berkovich's indentation in the normal direction, compared to the nickel coating, independent of the particle size. Moreover, the smallest the particle size used, the highest was the nanohardness of the composite coatings. However, there were no significant differences among the composite coatings concerning the applied lateral force, although all of them could support homogeneously frictional force compared to the pure nickel coating [38]. Similar results, concerning the hardness measurements, were found for zinc composite coating matrix reinforced with $\mathrm{TiO}_{2}$ particles (size between 100 and $200 \mathrm{~nm}$ ) [76]. The higher hardness of the coating was related to the fine-grained structure of the deposit. During hardness measurements, the dispersed particles in the fine-grained matrix might have obstructed the easy movement of dislocations, which was shown by the higher hardness values of compositecoated samples [76].

Nickel MMC coatings containing 7.9 and $11.5 \mathrm{wt} \% \mathrm{SiC}$ (particle size of $10 \mathrm{~nm}$ ), obtained by PC electrodeposition, also presented nanohardness values (3.98 \pm 0.032 and $4.10 \pm 0.065 \mathrm{GPa}$, 
respectively) higher than the value found for pure nickel coatings (3.00 $\pm 0.090 \mathrm{GPa})$ [75]. Considering the effect of the particle amount on hardness values, it is apparent that the higher hardness values were found for the electrodeposited nanocomposite with more SiC content in the coatings. The hardness values depended strongly on the embedded SiC particles in electrodeposited coatings [75]. Similar behavior was observed to composite coatings of Ni-Co reinforced with $\mathrm{SiC}$ particles, with size of $50 \mathrm{~nm}$ [37]. The authors observed that the composite coating obtained with $4.68 \mathrm{wt} \% \mathrm{SiC}$ in metallic matrix had maximum hardness (approximately $700 \mathrm{Hv}$ ) and minimum wear rate (approximately $2.0 \times 10^{-6} \mathrm{~mm}^{3} \mathrm{~N} \mathrm{~m}^{-1}$ ). The increase in the microhardness and the decrease in the wear rate of the $\mathrm{Ni}-\mathrm{Co} / \mathrm{SiC}$ nanocomposite coatings were explained by the grain fining and dispersive strengthening effects of the $\mathrm{SiC}$ nanoparticulates codeposited in the Ni-Co alloy matrix, which could have restrain the growth of the NiCo alloy grains and the plastic deformation of the matrix under loading. These effects became stronger as the nano-SiC content in the matrix increased, affecting the microhardness and the wear resistance of the $\mathrm{Ni}-\mathrm{Co} / \mathrm{SiC}$ composite coatings [37].

\section{Functional composite coatings with improved anticorrosive properties}

The amount of works in the literature concerning the production of functional MMC coatings with anticorrosive properties is relatively smaller than those works dealing with mechanical properties. As the anticorrosive performance of these MMC coating/substrate systems depend directly on the deposition parameters, the coatings must also be chemically, morphologically, and structurally characterized to make a relationship between the responses obtained with these analyses and the anticorrosive protection generated by the coating.

\subsection{Electrochemical techniques used to evaluate the anticorrosive properties of MMC coatings}

The anticorrosive properties of MMC coatings are investigated mainly using three electrochemical techniques: polarization curves, linear polarization resistance (LPR), and electrochemical impedance spectroscopy (EIS). A brief resume concerning the use of these techniques to evaluate electrodeposited coatings are now presented. More details about the techniques, however, can be found elsewhere [32,79-81].

\subsubsection{Polarization curves}

The polarization curves are used to evaluate the behavior of the coating/substrate system in a certain medium when the potential is varied from the corrosion potential of the system to both anodic and cathodic directions [56]. When the metal is far apart of its corrosion potential (more than $\pm 50 \mathrm{mV}$ ), it is said that the metal is polarized [32]. These curves are not related to one particular electrochemical reaction; instead, they show the overall effects of all reactions that occur simultaneously on the electrode [32].

The Tafel extrapolation of the straight part of the polarization curves permits the quantitative measurement of various electrochemical parameters very useful for corrosion evaluation. The 
most used are the corrosion potential $\left(\mathrm{E}_{\mathrm{corr}}\right)$, which shows the nobility of the coating compared to the substrate, and the corrosion current density $\left(\mathrm{j}_{\text {corr }}\right)$, which is related to the intensity of the corrosion process. Based on the $j_{\text {corr }}$ values, it is possible to calculate the corrosion rate and the coating efficiency $\left(\mathrm{Ef}_{\mathrm{Coat}}\right)[32,52]$ as well as to estimate the coating porosity [82]. It is also possible to determine the Tafel anodic and cathodic slopes $\left(\beta_{\mathrm{a}}\right.$ and $\beta_{\mathrm{c}^{\prime}}$ respectively), which are related to the kinetic aspects of the anodic and cathodic electrochemical reactions $[32,79]$.

The anodic branch of the polarization curve can also be used to study the passivity of the coatings and evaluate parameters such as the passivation potential $\left(\mathrm{E}_{\text {passivation }}\right)$, the critical current density for passivation $\left(\mathrm{j}_{\text {crit }}\right)$, and the pitting potential $\left(\mathrm{E}_{\text {pitting }}\right)$ [32].

\subsubsection{Linear polarization resistance}

LPR is a real-time technique regulated by the ASTM G59 standard method and is based on the potential variation around the open circuit potential (OCP; typical variations approximately $\pm 10 \mathrm{mV}$ [76] to $\pm 20 \mathrm{mV}$ are used) [83,84]. The current required to maintain a specific displacement of the resting potential is directly related to the corrosion process on the electrode surface. This technique is particularly useful in aqueous systems and is applicable to obtain the polarization resistance $\left(R_{p}\right)$ [75]. It is also possible to calculate the current and the corrosion rate if the values of $R_{p}$ and the Tafel slopes are known [32,83]. In addition, it is possible to evaluate the porosity of the coating by comparing the $R_{p}$ values of the coating and of the substrate [82].

\subsubsection{Electrochemical impedance spectroscopy}

EIS is a technique that provides detailed information on the electrical characteristics of the electrode/solution interface. EIS is based on the application of a small sinusoidal signal of potential (or current) to the working electrode according to a particular desired frequency range. As a response, it obtained the impedance $(Z)$, which can be related to the opposition to the current flux in the system [32]. Important information about the charge transfer kinetics, structure, and properties of the interface electrode/electrolyte can also be achieved. The frequency range usually used for disturbing the system varies from $100 \mathrm{kHz}$ to $10 \mathrm{MHz}$, using the amplitude signal in the range of 5 to $50 \mathrm{mV} \mathrm{rms}$, depending on the studied system $[32,85]$.

The results obtained from the EIS measurements can be used to construct diagrams representing the behavior of the electrode in a particular electrochemical process. One of these diagrams is the Nyquist diagram, in which the real $(Z)$ and imaginary $(Z)$ impedance data are represented in a complex plane. The real impedance $(Z)$ incorporates the ohmic resistance (i.e., the pure resistance that is independent of the frequency). The imaginary impedance $(Z)$ incorporates the capacity and/or inductive reactance (i.e., the resistance that is dependent on the frequency applied to the system) [32].

The Bode and phase diagrams are also used to represent the EIS results. These diagrams show the variations of the impedance modulus $(|Z|)$ or the phase angle with the frequency, respectively. An advantage of the Bode diagram is the possibility of observing the impedance 
variation at high frequencies, which is generally omitted in the Nyquist diagram representation [32].

EIS can be considered as a nondestructive technique $[32,85,86]$. The application of this technique in electrochemical systems considers the combination of physical and chemical interfacial processes with the components of an equivalent electrical circuit as an analogy of the electrochemical phenomena. Therefore, it is possible to obtain the electrolyte resistance $\left(R_{e}\right)$, the charge transfer resistance $\left(R_{c t}\right)$, the polarization resistance $\left(R_{p}\right)$, and the double layer capacitance $\left(\mathrm{C}_{\mathrm{dl}}\right)$ as variables that allow the assessment of coating/substrate characteristics $[32,86]$. In addition, it is also possible to evaluate the corrosion rate and the porosity of the coating by comparing the $R_{p}$ values of the coating and of the substrate in the same electrolytic medium [32,82].

\subsection{Main results concerning the corrosion resistance of MMC coatings}

The comparison between the anticorrosive performance of metallic and MMC coatings was studied for several metallic matrix/ceramic particles (or nanoparticles) systems using different corrosive media $[26,37,40,45,47]$. Most of the results affirm that the presence of the particles increases the corrosion resistance of the MMC coating/substrate system, although it is important to mention that the optimum values of particle content in the metallic matrix to produce a coating with good anticorrosive performance directly depend on the metal/particle system produced and on the deposition parameters used. Moreover, the corrosion mechanism of the metallic coatings containing these particles is not completely elucidated; the process is generally related to blocking effects or to the creation of a more difficult path to the electrolyte attack in the coating $[47,58,75,87]$. In addition, there are also inconclusive results, as the conditions used to produce the coatings were not always adequate or the used parameters were not always completely mentioned (for example, the kind of substrate or the stirring time). Finally, the results presented here also show that the deposition parameters earlier described may have synergistic and/or antagonistic effects on the coating deposition process and on the anticorrosive properties of the coatings.

\subsubsection{Ni and Ni-alloy matrix composite coatings}

Nickel is the most studied metallic matrix to produce composite coatings with improved corrosion properties, and different ceramic particles and nanoparticles were used to this purpose. The corrosion resistance of nickel matrix composite coatings using $\alpha-\mathrm{Al}_{2} \mathrm{O}_{3}$ particles (smaller than $1 \mu \mathrm{m} ; 98 \%$ purity) as the second phase on steel substrate, compared to a standard nickel coating produced onto the same substrate, was studied [87]. The corrosion evaluation data of the coating/substrate systems (from polarization curves and electrochemical impedance experiments) were performed in 0.5 mol L-1 $\mathrm{Na}_{2} \mathrm{SO}_{4}$ solution with different exposure times. Despite the physical (defects and dislocations) and chemical heterogeneities (the presence of nickel oxides or impurities), $\mathrm{Al}_{2} \mathrm{O}_{3}$ particles in the nickel coatings disturbed the electrochemical electrode reactions. As a result, the corrosion process was enhanced in some parts of the coating, whereas the phenomenon was inhibited in other parts. Therefore, no significant differences were observed concerning the anticorrosive behavior of the standard 
nickel coating and of the composite coating for the data obtained in the first days of exposure. Although the corrosion rates of both coatings increased with the exposure time, the corrosion resistance of $\mathrm{Ni} / \mathrm{Al}_{2} \mathrm{O}_{3}$ composite coatings was always higher than the standard nickel coating in $\mathrm{Na}_{2} \mathrm{SO}_{4}$. Because of the adsorption of water, $\mathrm{OH}^{-}$ions, and oxygen, the surfaces of both coatings were covered with a thin layer of nickel oxides and hydroxides causing an increase in $R_{\mathrm{ct}}$ during the first 3 days of the experiment [87].

The EIS measurements showed that this result was related to the fact that the resistance of the electrolyte in the pores of the composite coating was much lower than in the pores of the standard nickel coating. It means that the presence of $\mathrm{Al}_{2} \mathrm{O}_{3}$ particles in the voids of the coating increases its porosity and the discontinuity of the passive layer formed on its surface. In the cracks and pores of the passive layer, the electrolytic solution is in contact with either nickel or dielectric $\mathrm{Al}_{2} \mathrm{O}_{3}$ particles. However, the passive layer on the surface of the $\mathrm{Ni} / \mathrm{Al}_{2} \mathrm{O}_{3}$ coating was tighter possibly due to the more finely crystalline structure of the composite coating in comparison with that of the nickel standard coating. As a result, the pores and cracks in the passive layer on the composite coating were sufficiently small to reduce the diffusion of metal corrosion products from their inside effectively, and they built up in the pores, blocking them and decreasing the corrosion process [87]. After 14 days of exposure in the corrosive medium, the corrosion rate of the $\mathrm{Ni} / \mathrm{Al}_{2} \mathrm{O}_{3}$ composite coating was three times lower than that of the nickel coating.

$\mathrm{Ni} / \mathrm{CeO}_{2}$ composite coatings were produced on steel from an acid electrolyte containing $\mathrm{CeO}_{2}$ nanoparticles using square-wave pulse current mode under different stirring speed conditions and at $45^{\circ} \mathrm{C}$. The corrosion behavior of these coatings was evaluated in a $3.5 \mathrm{~g} \mathrm{~L}^{-1}$ $\mathrm{NaCl}$ solution and compared to that observed from a nickel coating in the same medium [47]. More positive corrosion potentials and higher $R_{p}$ values were obtained for the composite coatings (ranging from $3.54 \times 10^{3}$ to $9.772 \times 10^{3} \Omega$ ) compared to those verified for the nickel coating $\left(2.05 \times 10^{3} \Omega\right)$. Once more, the presence of the inert particles in the coating was considered important in the improvement of the corrosion resistance of composite coating because they may have acted as a physical barrier to the propagation of defects. The dispersion of the nanoparticles in the metallic matrix formed corrosion microcells, which facilitated the anodic polarization, resulting in the inhibition of pitting corrosion and in the promotion of uniform corrosion of the coating. If the crystallites in the coating remained on their nanometer size, the corrosion process could be explained considering that the electrolyte must travel a tortuous path to reach the substrate and this path is longer in the $\mathrm{Ni} / \mathrm{CeO}_{2}$ composite coatings than in the nickel coating [47].

The increase in the stirring speed until $450 \mathrm{rpm}$ increased the $\mathrm{CeO}_{2}$ particles in the nickel matrix coating, as well as the $R_{p}$ values measured for these coatings, indicating a relationship between the content of particles in coating and its anticorrosive performance. Further increase in stirring speed, however, decreased both the particle incorporation and the $R_{p}$ value, showing that it must be an optimum stirring speed condition to produce coatings with high corrosion resistance [47]. However, the effects of the pulse plating and the deposition temperature on the corrosion performance of the coating/substrate system were not evaluated. 
EIS analysis was performed in aqueous $\mathrm{NaOH}\left(1 \mathrm{~mol} \mathrm{~L}^{-1}\right)$ and $\mathrm{HNO}_{3}\left(1 \mathrm{~mol} \mathrm{~L}^{-1}\right)$ solutions to evaluate the anticorrosive properties of $\mathrm{Ni} / \mathrm{TiO}_{2}$ nanocomposite coatings. The coatings containing different $\mathrm{TiO}_{2}$ contents, (A: Ni-3.9 wt $\% \mathrm{TiO}_{2}$, B: Ni-6.5 wt $\% \mathrm{TiO}_{2}$, and C: Ni-8.3 wt $\% \mathrm{TiO}_{2}$ ) were produced onto steel from an acid $\mathrm{Ni}(\mathrm{II})$ bath. The charge transfer resistances of pure nickel and $\mathrm{Ni}-\mathrm{TiO}_{2}$ coatings [49] are shown in Table 3.

\begin{tabular}{ccc}
\hline & $\mathbf{R}_{\mathrm{ct}}\left(\boldsymbol{\Omega} \mathrm{cm}^{2}\right) \times 10^{3}$ & \\
\hline Coatings & $\mathrm{NaOH}$ & $\mathrm{HNO}_{3}$ \\
\hline Pure Ni & 203 & 2.0 \\
\hline A & 383 & 3.3 \\
\hline B & 491 & 3.9 \\
\hline C & 634 & 4.3 \\
\hline
\end{tabular}

Table 3. Charge transfer resistance for pure nickel coating and $\mathrm{Ni}-\mathrm{TiO}_{2}$ nanocomposite coatings (A-C) obtained from EIS data [49] after fitting by the equivalent circuit model

The Nyquist diagrams obtained from the experiments carried out in $\mathrm{NaOH}$ showed a capacitive loop at high frequencies followed by an almost straight line at low frequencies, suggesting that the corrosion mechanism was controlled by both charge transfer and diffusion processes. The corrosion rate was affected by the interdiffusion of $\mathrm{Ni}^{2+}$ and $\mathrm{OH}^{-}$ions, confirming that there should be an effect related to the diffusion of these ions in the coating. The $\mathrm{R}_{\mathrm{ct}}$ values for the composite coatings exposed in this medium were improved with the increase of the $\mathrm{TiO}_{2}$ nanoparticle content in the coating, because they probably decreased the diffusion process [49].

In the experiments performed in $\mathrm{HNO}_{3}$, there was an observed discrete capacitive loop at high frequencies of the Nyquist diagram. An inductive loop was also observed at low frequencies, which was attributed to the relaxation process of $\mathrm{H}^{+}$and $\mathrm{NO}^{3-}$ species adsorbed on the electrode surface [49]. As observed in the experiments carried out in $\mathrm{NaOH}$ medium, the increase in the $\mathrm{TiO}_{2}$ content in the coating caused an increase in the charge transfer resistance of the composite coating. However, the $\mathrm{R}_{\mathrm{ct}}$ values obtained in acidic medium were significantly smaller than those verified in alkaline medium [49]. These results suggested that the acidic medium may have damaged the coating or that the corrosion mechanism has changed in this medium.

The presence of different concentrations of sodium dodecyl sulfate (SDS) in the electrodeposition bath to produce nickel $/ \alpha-\mathrm{Al}_{2} \mathrm{O}_{3}$ and its influence on the anticorrosive performance of the coating produced onto steel in $\mathrm{NaCl}(3.5 \% \mathrm{~m} / \mathrm{v})$ was also studied [8]. Although the use of a surfactant may enhance the incorporation of inert particle in the metallic matrix, it also has some disadvantages, as they can be incorporated in the metallic matrix and change the mechanical properties of the deposit (e.g., internal stress and fragility). This is why the concentration of surfactants in the deposition bath should be very well controlled [88]. The nanocomposite coatings produced using the optimum SDS concentration $\left(125 \mathrm{~g} \mathrm{~L}^{-1}\right)$ contained higher levels of alumina nanoparticles in the metallic matrix. This coating presented a more positive corrosion potential $\left(\mathrm{E}_{\text {corr }}=-0.209 \mathrm{~V}_{\mathrm{Ag} / \mathrm{AgCl}}\right)$ and a lower corrosion current density $\left(\mathrm{j}_{\text {corr }}=\right.$ 
$\left.1.141 \times 10^{-7} \mathrm{~A} \mathrm{~cm}^{-2}\right)$ than the bare substrate $\left(\mathrm{E}_{\text {corr }}=-0.488\right.$ and $\left.\mathrm{j}_{\text {corr }}=4.832 \times 10^{-6} \mathrm{~A} \mathrm{~cm}^{-2}\right)$. It was considered that the incorporation of such low reactive nanometer alumina particles played an important role in improving the corrosion resistance of the coating/substrate system, as they apparently filled the pores and micropores of the coating and thereby reduced the corrosion process [8].

The corrosion performance of Ni-Co alloy matrix composite coatings containing different contents of SiC nanoparticles was evaluated [37]. The coatings were produced onto copper substrate from acid $\mathrm{Ni}(\mathrm{II})$ and $\mathrm{Co}(\mathrm{II})$ sulfamate solutions using DC and different stirring speeds. The polarization curves of both the composite coatings and the Ni-Co alloy coatings were performed in a $0.5 \mathrm{~mol} \mathrm{~L}^{-1} \mathrm{NaCl}$ solution. It was found that the composite coating produced at $0.03 \mathrm{~A} \mathrm{~cm}^{-2}$ contained $3.2 \mathrm{wt} \% \mathrm{SiC}$ and that this coating showed a lower corrosion current density and a more positive corrosion potential $\left(\mathrm{E}_{\mathrm{corr}}=-0.33 \mathrm{~V}_{\mathrm{SCE}}, \mathrm{j}_{\mathrm{corr}}=7.9 \times 10^{-3} \mathrm{~A} \mathrm{~cm}^{-2}\right)$ compared to the results of a Ni-Co alloy coating $\left(\mathrm{E}_{\mathrm{corr}}=-0.39 \mathrm{~V}_{\mathrm{SCE}}, \mathrm{j}_{\mathrm{corr}}=3.98 \times 10^{-2} \mathrm{~A} \mathrm{~cm}^{-2}\right)$. The better result obtained by this nanocomposite coating was attributed to a decrease in the size of the defects related to the incorporation of $\mathrm{SiC}$ nanoparticles, which is useful for creating a tortuous path to the corrosive medium attack the substrate, preventing pitting corrosion and enhancing the corrosion resistance of these nanocomposite coatings [37]. However, the results concerning $\mathrm{Ni}-\mathrm{Co} / \mathrm{SiC}$ coatings containing other $\mathrm{SiC}$ contents were not mentioned in the work.

Composite coatings of Ni-Zn matrix containing $\mathrm{TiO}_{2}$ nanoparticles (Degussa P-25 anatase, 25 $\mathrm{nm}$ ) as the strengthening phase were produced onto a mild steel (DIN C25-AISI 1025) substrate using ultrasonic-assisted electrodeposition process [89]. These coatings were electrochemically evaluated in a natural $3.5 \mathrm{wt} \% \mathrm{NaCl}$ solution using EIS measurements at the OCP. The results showed that higher $R_{c t}$ values were obtained for samples produced using 108 and $216 \mathrm{~W}$ $\mathrm{cm}^{-2}$ of ultrasonic powder densities, indicating a better anticorrosion performance of these coatings. On the contrary, the $\mathrm{R}_{\mathrm{ct}}$ values of coatings produced without using the ultrasonicassisted process were smaller than that obtained for the alloy Ni-Zn coating. The authors claim that the use of ultrasonic vibration together with electrodeposition might have improved the coating nanoparticles uniform dispersion and hence improved the anticorrosive ability of the composite coatings [89].

\subsubsection{Copper matrix composite coatings}

The corrosion behavior of electrodeposited $\mathrm{Cu} / \mathrm{SiO}_{2}$ nanocomposite coatings, produced onto steel (OL 37) in a bath containing (or not) a surfactant agent $\left.\mathrm{C}_{16} \mathrm{H}_{33} \mathrm{~N}_{(} \mathrm{CH}_{3}\right)_{3} \mathrm{Br}$ (CTAB) in different concentrations, was evaluated in $0.2 \mathrm{~g} \mathrm{~L}^{-1} \mathrm{Na}_{2} \mathrm{SO}_{4}$ solution at room temperature and $\mathrm{pH} 3$ [45]. A decrease of the corrosion current density for the composite deposit $\mathrm{Cu} / \mathrm{SiO}_{2}$ was also observed in comparison with the pure copper coating, suggesting that the presence of nanoparticles had a beneficial effect in decreasing the corrosion rate as shown in Table 4 . These results were confirmed by the $R_{p}$ values obtained from a linear polarization experiment in the same corrosion medium. This behavior was explained by the lowering of the electrode surface area in contact with the electrolyte due to the presence of the nanoparticles and by a more finegrained compact structure of the coating. 


\begin{tabular}{cccc}
\hline Coating & $\mathrm{E}_{\text {corr }}\left(\mathbf{V}_{\mathrm{Ag} / \mathrm{AgCl}}\right)$ & Average of $\mathbf{j}_{\text {corr }}\left(\mathbf{A ~ \text { cm} ^ { - 2 } )}\right.$ & $\begin{array}{c}\mathbf{R}_{\mathrm{p}} \\
\left(\Omega \mathbf{c m}^{2}\right)\end{array}$ \\
\hline $\mathrm{Cu}$ & -0.588 & $75 \times 10^{-6}$ & 500 \\
\hline $\mathrm{Cu}-\mathrm{SiO}_{2}$ (A) & -0.563 & $40 \times 10^{-6}$ & 1000 \\
\hline $\mathrm{Cu}-\mathrm{SiO}_{2}$ (B) & -0.597 & $30 \times 10^{-6}$ & 1341 \\
\hline $\mathrm{Cu}-\mathrm{SiO}_{2}$ (C) & -0.592 & $40 \times 10^{-6}$ & 628 \\
\hline $\mathrm{Cu}-\mathrm{SiO}_{2}$ (D) & -0.578 & $20 \times 10^{-6}$ & 1769 \\
\hline
\end{tabular}

*The composite coatings were produced from $\mathrm{Cu}$ (II) solutions containing $\mathrm{SiO}_{2} 10 \mathrm{~g} \mathrm{~L}^{-1}+\mathrm{CTAB}$ (A) $0.00 \mathrm{~mol} \mathrm{~L}^{-1}$, (B) $10^{-5}$ $\mathrm{mol} \mathrm{L}{ }^{-1},(\mathrm{C}) 10^{-4} \mathrm{~mol} \mathrm{~L}^{-1}$, and (D) $10^{-3} \mathrm{~mol} \mathrm{~L}^{-1}$.

Table 4. Corrosion data for $\mathrm{Cu}$ and $\mathrm{Cu}-\mathrm{SiO}_{2}$ deposits obtained by Zamblau et al. [45] in the absence and presence of different concentrations of CTAB.

The increase of $\mathrm{CTAB}$ concentration in the electrolyte hindered the corrosion process even more when CTAB concentration was increased from $1.0 \times 10^{-5}$ to $1.0 \times 10^{-2} \mathrm{~mol} \mathrm{~L}^{-1}$ and then to $1.0 \times 10^{-3} \mathrm{~mol} \mathrm{~L}^{-1}$. As the surfactant increased the incorporation of $\mathrm{SiO}_{2}$ in the coating by modifying the surface charge of the nanoparticles (the negative initial charge turns into a positive one) and their hydrophilicity, the anticorrosive performance of the coating was enhanced [89]. The highest $R_{p}$ value was obtained for a bath containing $10 \mathrm{~g} \mathrm{~L}^{-1} \mathrm{SiO}_{2}$ and $1.0 \times 10^{-3} \mathrm{~mol} \mathrm{~L}^{-1} \mathrm{CTAB}$, confirming the good effect of this additive in the electrolytic deposition of metal-nanoparticle composites [45].

The protective and anticorrosive properties of copper coatings, $\mathrm{Cu}+\mu \mathrm{SiC}$ composite coatings (particle size of $1-2 \mu \mathrm{m}$ ), and $\mathrm{Cu}+n \mathrm{SiC}$ composite coatings (particle size of $20 \mathrm{~nm}$ ), produced on standardized steel Q-pane, were evaluated by potentiodynamic curves in two different environments. An acidic solution $\left(0.5 \mathrm{~mol} \mathrm{~L}^{-1} \mathrm{Na}_{2} \mathrm{SO}_{4}\right.$ at $\left.\mathrm{pH} 2\right)$ was used to evaluate the uniform corrosion rate, whereas an alkaline solution $\left(0.5 \mathrm{~mol} \mathrm{~L}^{-1} \mathrm{Na}_{2} \mathrm{SO}_{4}\right.$ at $\left.\mathrm{pH} 12\right)$ was employed to evaluate if the presence of the particles influenced the passive potential range and current [91]. Table 5 shows that, in acidic environment, the specimens coated by the $\mathrm{Cu}+\mu \mathrm{SiC}$ composite deposit presented the most negative corrosion potential and the highest corrosion rate, expressed by the corrosion current density $\left(\mathrm{j}_{\text {corr }}=5.0 \mu \mathrm{A} \mathrm{cm}{ }^{-2}\right)$. This behavior was attributed to the voids between the ceramic particles and the metallic matrix that allow the access of the electrolyte to the substrate. These voids were larger in the $\mathrm{Cu}+\mu \mathrm{SiC}$ composite coatings than in the $\mathrm{Cu}+n \mathrm{SiC}$ composite ones. In fact, the value of the corrosion potential of the $\mathrm{Cu}+\mu \mathrm{SiC}$ composite coatings was comparable to the value obtained by this research group for the bare steel substrate in the same acidic corrosion medium. On the contrary, the $\mathrm{Cu}+n \mathrm{SiC}$ composite coating samples presented no differences in the corrosion potential compared to the pure copper coatings. However, the nanocomposite samples showed a lower corrosion current density and, consequently, a lower corrosion rate than the copper coating, which might be attributed to their more compact microstructure [91].

Nevertheless, the potentiodynamic curves obtained in the alkaline environment showed no differences for the three types of coatings before their passivation. The two composite coatings 


\begin{tabular}{ccc}
\hline Coating & $\mathbf{E}_{\text {corr }}\left(\mathbf{V}_{\mathrm{Ag} / \mathrm{AgCl}}\right)$ & $\mathbf{j}_{\text {corr }}\left(\mu \mathbf{A ~ \mathbf { ~ m } ^ { - 2 } )}\right.$ \\
\hline $\mathrm{Cu}$ & -0.053 & 0.7 \\
\hline $\mathrm{Cu}-\mu \mathrm{SiO}_{2}$ & -0.456 & 5.0 \\
\hline $\mathrm{Cu}-n \mathrm{SiO}_{2}$ & -0.013 & 0.3 \\
\hline
\end{tabular}

Table 5. Results for corrosion evaluation of $\mathrm{Cu}, \mathrm{Cu}-\mu \mathrm{SiO}_{2}$, and $\mathrm{Cu}-n \mathrm{SiO}_{2}$ deposits produced by Lekka et al. [91] in acidic ( $\mathrm{pH}$ 2) $0.5 \mathrm{~mol} \mathrm{~L}^{-1} \mathrm{Na}_{2} \mathrm{SO}_{4}$ solution.

showed an improved passive domain in comparison to the pure copper coating, with only one, continuous, and stable passive zone. On the contrary, the pure metallic coating presented two passive regions corresponding to the formation of two different types of oxides. The voids between the $\mathrm{SiO}_{2}$ microparticles and the metallic matrix earlier mentioned seemed to cause no influence on the behavior of the $\mathrm{Cu}-\mu \mathrm{SiO}_{2}$ composite coating in an alkaline environment because the compact oxide film could have covered them. The samples covered by the $\mathrm{Cu}+n \mathrm{SiC}$ composite coatings also presented the lowest passive current density. Thus, the compact microstructure of the $\mathrm{Cu}+n \mathrm{SiC}$ composite coatings also led to the formation of a compact and protective oxide in alkaline solutions [91].

The cathodic efficiency and consequently the thickness of the $\mathrm{Cu}-\mu\left(\gamma-\mathrm{Al}_{2} \mathrm{O}_{3}\right)$ coatings produced from pyrophosphate bath decreased with the increase (in modulus) of the cathodic potential $(E)$ independent of the previous stirring time $(t)$ used [61]. Thinner coatings can directly influence the anticorrosive performance of the coatings. On the contrary, Figure 6 indicates that there may be a joint influence of both parameters, $E$ and $t$, in the coating composition, although none of them alone presented a significant influence.

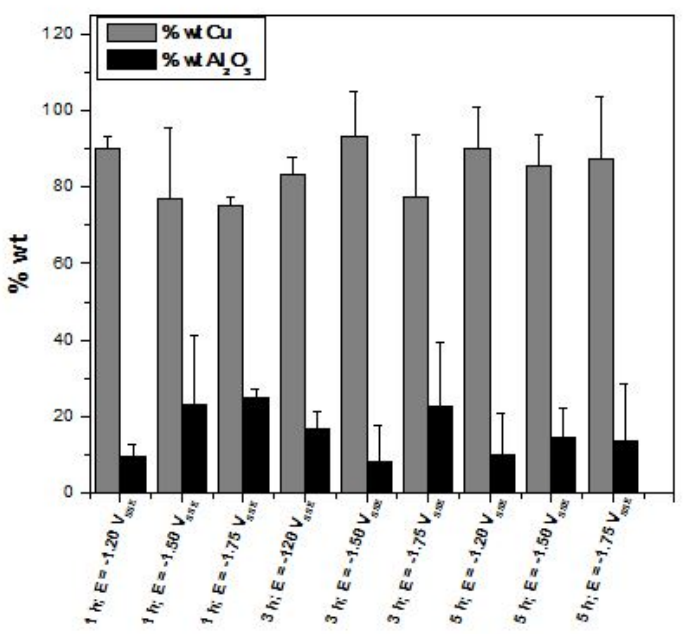

Figure 6. $\mathrm{Cu}$ and $\mathrm{Al}_{2} \mathrm{O}_{3}$ contents (wt\%) in the composite coatings produced from baths containing $\mathrm{CuSO}_{4} 0.02 \mathrm{~mol} \mathrm{~L}^{-1}$, $\mathrm{K}_{4} \mathrm{P}_{2} \mathrm{O}_{7} 0.90 \mathrm{~mol} \mathrm{~L}^{-1}$, and $\gamma-\mathrm{Al}_{2} \mathrm{O}_{3}$. 
Although there was no direct relationship between the applied cathodic potential and the $\gamma$ $\mathrm{Al}_{2} \mathrm{O}_{3}$ content in the coating, the increase in this parameter also seemed to increase the dispersion of the particles in the coating, as shown in Figures 7 and 8, for the coatings produced after $5 \mathrm{~h}$ of stirring at $(800 \mathrm{rpm})$.

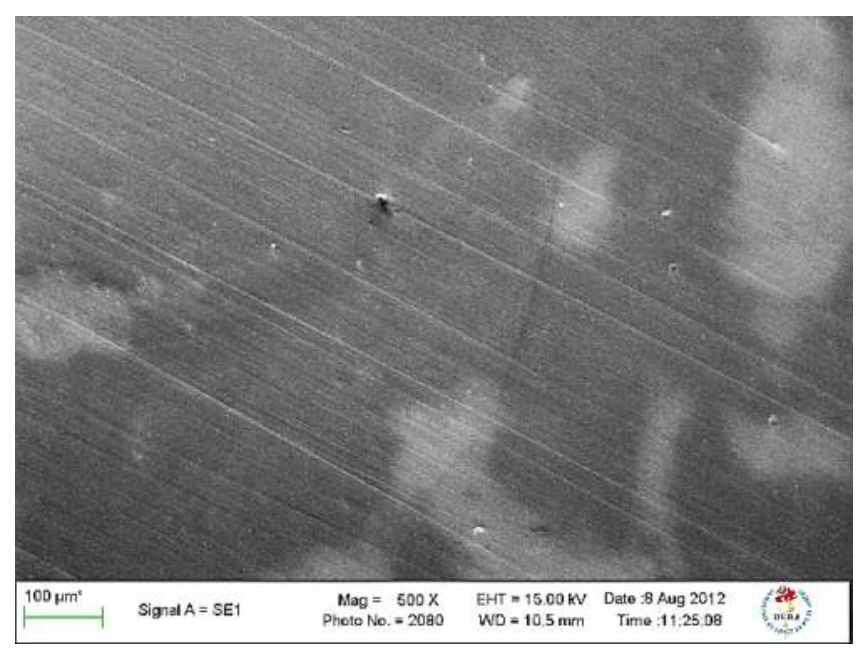

Figure 7. Surface morphology of $\mathrm{Cu} / \gamma-\mathrm{Al}_{2} \mathrm{O}_{3}$ coatings produced at $-1.20 \mathrm{~V}_{\text {SSE }}$ from pyrophosphate bath previously stirred for $5 \mathrm{~h}$ at $800 \mathrm{rpm}[61]$.

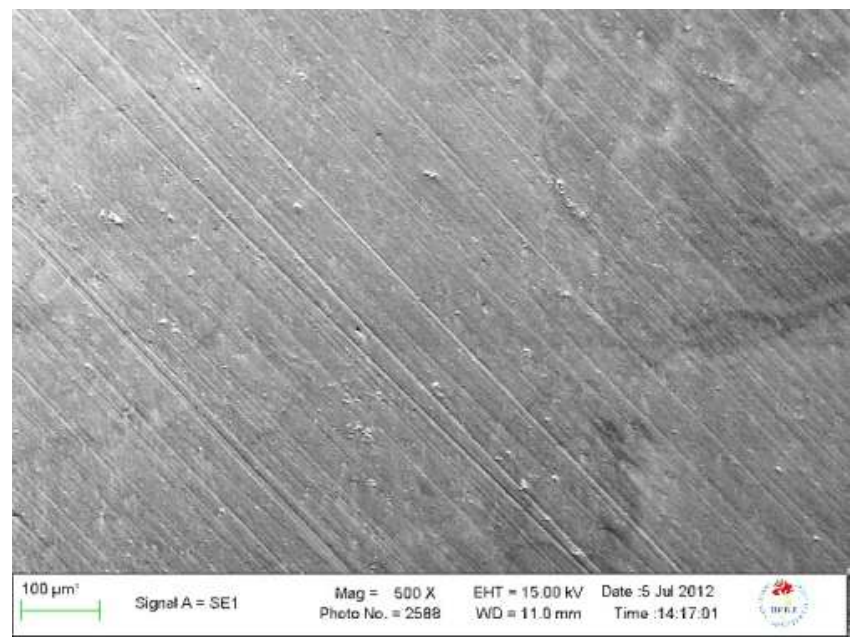

Figure 8. Surface morphology of $\mathrm{Cu} / \gamma-\mathrm{Al}_{2} \mathrm{O}_{3}$ coatings produced at $-1.50 \mathrm{~V}_{\text {SSE }}$ from pyrophosphate bath previously stirred for $5 \mathrm{~h}$ at $800 \mathrm{rpm}[61]$. 
It was expected that a coating presenting a well-dispersed second phase and a high amount of micrometric $\gamma-\mathrm{Al}_{2} \mathrm{O}_{3}$ particles presented the best anticorrosive performance. However, these effects had no direct influence on the corrosion performance of these coatings in $0.5 \mathrm{~mol} \mathrm{~L}^{-1}$ $\mathrm{NaCl}$, and no significant differences could be noted among their $\mathrm{E}_{\text {corr }}$ as shown in Table 5 and Figure 9 , whereas the $j_{\text {corr }}$ values increased when the applied potential became more negative. Moreover, the anticorrosive performance of these coatings, in terms of $j_{\text {corr }}$, was worse than the values obtained for the pure copper coating $\left(5.27 \mu \mathrm{A} \mathrm{cm} \mathrm{cm}^{-2}\right)$. The thin layers produced under the deposition conditions could have probably masked the effects of the deposition parameters on the anticorrosive performance of these coatings. In addition, the micrometric size of the $\gamma$ $\mathrm{Al}_{2} \mathrm{O}_{3}$ particles could have contributed to create defects and voids in the coatings, enhancing the corrosion process, confirming the results earlier shown for $\mathrm{Cu}-\mu \mathrm{SiO}_{2}$ coatings [91], and showing that the size of the particle is an important parameter to produce composite coatings with high anticorrosive characteristics.

\begin{tabular}{cccc}
\hline Experiments & $\begin{array}{c}\text { Applied cathodic potencial } \\
\left(\mathbf{V}_{\text {SSE }}\right)\end{array}$ & $\mathbf{j}_{\text {corr }}\left(\mu \mathrm{A} \mathrm{cm}^{-2}\right)$ & $\mathbf{E}_{\text {corr }}\left(\mathbf{V}_{\mathrm{SCE}}\right)$ \\
\hline 1 & -1.20 & 10.3 & -0.411 \\
\hline 2 & -1.50 & 62.2 & -0.423 \\
\hline
\end{tabular}

Table 6. and $\mathrm{E}_{\text {corr }}$ values of composite coatings $\mathrm{Cu} / \gamma-\mathrm{Al}_{2} \mathrm{O}_{3}$ in $0.5 \mathrm{~mol} \mathrm{~L}-1 \mathrm{NaCl}$. The coatings were produced at -1.20 and $-1.50 \mathrm{~V}_{\mathrm{SSE}}$ after previous stirring for $5 \mathrm{~h}$ of at $800 \mathrm{rpm}$ [61].

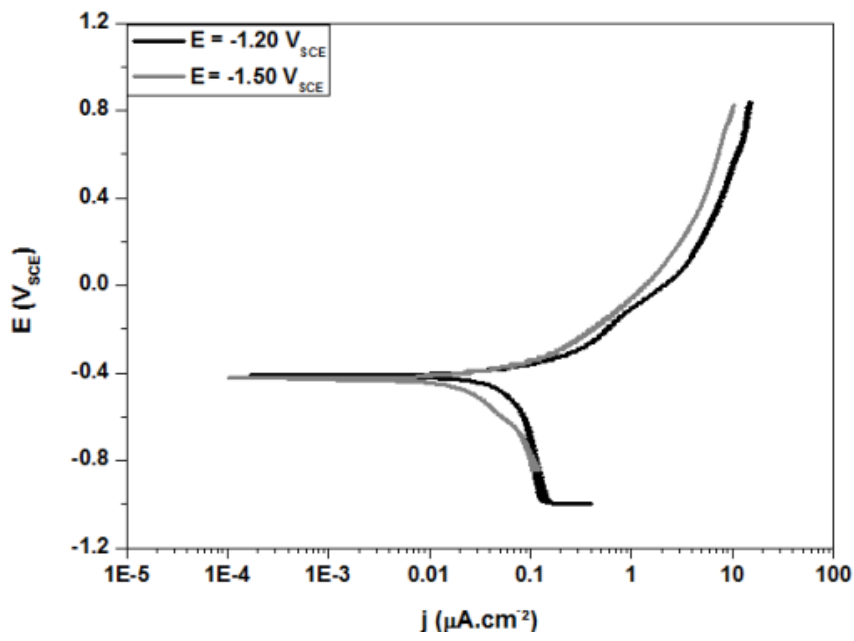

Figure 9. Polarization curves of $\mathrm{Cu} / \gamma-\mathrm{Al}_{2} \mathrm{O}_{3}$ coatings/steel substrate systems in $0.5 \mathrm{~mol} \mathrm{~L}^{-1} \mathrm{NaCl}$.

$\mathrm{Cu} /$ boehmite nanocomposite coatings $[\mathrm{AlO}(\mathrm{OH})$ Disperal P2, $25 \mathrm{~nm}$ size; Sasol®] was produced onto steel substrate (AISI 1020) by DC electrodeposition using $\mathrm{j}=7.0$ and $21.0 \mathrm{~A}$ 
$\mathrm{m}^{-2}$ from a pyrophosphate bath, containing (or not) allyl alcohol as an additive agent, under 1000 and $1300 \mathrm{rpm}$ of stirring speed [61]. The allyl alcohol has been reported in the literature as a brightening agent and relieving stress in the production on $\mathrm{Cu}$ coatings and $\mathrm{Cu}-\mathrm{Zn}$ alloy [92]. The corrosion resistances from these coatings were obtained using the linear polarization experiments $\left(R_{p}\right)$. The results showed that the presence of allyl alcohol improved the corrosion resistance of the composite coatings in $0.1 \mathrm{~mol} \mathrm{~L}^{-1} \mathrm{Na}_{2} \mathrm{SO}_{4}$ compared to those produced from baths without this additive under the same deposition conditions [61]. For example, the composite coating produced at $1000 \mathrm{rpm}$ and $7 \mathrm{~A} \mathrm{~m}^{-2}$ presented $R_{\mathrm{p}}=2956 \Omega$, when a bath without allyl alcohol was used, and $\operatorname{Rp}=2.0 \times 10^{7} \Omega$, when a bath containing this additive was employed. This behavior can be related to the effect of this type of compound, usually used to refine the coatings in an electrodeposition process and favor the formation of layers without cracks or defect, improving the corrosion resistance [92].

\section{Conclusions}

It is possible to conclude that, although composite coatings have been under investigation for many years, their application as anticorrosive coatings still needs more research. The effects of the electrical nature of the particle and the bath composition (e.g., complexant, additives, and surfactants) on the anticorrosive characteristics of the MMC coatings must be studied. Other parameters, such as stirring speed, previous stirring time, and solution temperature, must also be optimized to enhance the incorporation of the nanoparticles to the coatings and relate this effect to their anticorrosive properties. In addition, the corrosion processes in different electrolytic media must be evaluated and be related with the deposition parameters. Therefore, there is a great research opportunity involving the production of MMC coatings by electrodeposition and their characterization as anticorrosive coatings.

\section{Author details}

Thais G.L. Rezende, Deborah V. Cesar, Dalva C.B. do Lago and Lilian F. Senna*

*Address all correspondence to: 1senna@uerj.br

Laboratório de Eletroquímica e Corrosão, Departamento de Química Analítica, Universidade do Estado do Rio de Janeiro, Rio de Janeiro, RJ, Brazil

\section{References}

[1] Oniciu L., Muresan L. Some fundamental aspects of levelling and brightening in metal electrodeposition. Journal of Applied Electrochemistry. 1991; 21(7): 565-574. DOI: 10.1007/BF01024843. 
[2] Adamian R. Novos Materiais Tecnologias e Aspectos Econômicos. Rio de Janeiro: Setor de Publicações e Programação Visual/COPPE/UFRJ; 2009. 400 p.

[3] Callister W.D. Materials Science and Engineering: An Introduction. $7^{\text {th }}$ ed. USA: John Wiley \& Sons, Inc.; 2006. 832 p.

[4] Malfatti C.F. Estudo das propriedades de revestimentos compósitos de níquel com $\mathrm{Al}_{2} \mathrm{O}_{3}$ e $\mathrm{SiC}$ [dissertation]. Porto Alegre, RS: Universidade Federal do Rio Grande do Sul; 2000. 118 p. Available from: http://hdl.handle.net/10183/3428.

[5] Musiani M. Electrodeposition of composites: An expanding subject in electrochemical materials science. Electrochimica Acta. 2000; 45(20): 3397-3402. DOI: 10.1016/ S0013-4686(00)00438-2.

[6] Tuaweri T.J., Wilcox G.D. Behaviour of $\mathrm{Zn}-\mathrm{SiO}_{2}$ electrodeposition in the presence of N,N-dimethyldodecylamine. Surface and Coatings Technology. 2006; 200(20-21): 5921-5930. DOI: 10.1016/j.surfcoat.2005.09.023.

[7] Wang Y.L., Wan Y.Z., Zhao Sh.M., Tao H.M., Dong X.H. Electrodeposition and characterization of $\mathrm{Al}_{2} \mathrm{O}_{3}-\mathrm{Cu}(\mathrm{Sn}), \mathrm{CaF}_{2}-\mathrm{Cu}(\mathrm{Sn})$ and talc- $\mathrm{Cu}(\mathrm{Sn})$ electrocomposite coatings. Surface and Coatings Technology. 1998; 106(2-3): 162-166. DOI: 10.1016/ S0257-8972(98)00522-2.

[8] Sabri M., Sarabi A.A., Kondelo S.M.N. The effect of sodium dodecyl sulfate surfactant on the electrodeposition of Ni-alumina composite coatings. Materials Chemistry and Physics. 2012; 136(2-3): 566-569. DOI: 10.1016/j.matchemphys.2012.07.027.

[9] Bund A., Thiemig D. Influence of bath composition and $\mathrm{pH}$ on the electroco-deposition of alumina nanoparticles and copper. Journal of Applied Electrochemistry. 2007; 37(3): 345-351. DOI: 10.1007/s10800-006-9264-2.

[10] Gül H., Kiliç F., Aslan S., Alp A., Akbulut H. Characteristics of electro-co-deposited $\mathrm{Ni}-\mathrm{Al}_{2} \mathrm{O}_{3}$ nano-particle reinforced metal matrix composite (MMC) coatings. Wear. 2009; 256: 976-990. DOI: 10.1016/j.wear.2008.12.022.

[11] Stankovic V.D., Gojo M. Electrodeposited composite coatings of copper with inert, semiconductive and conductive particles. Surface and Coatings Technology. 1996; 81(2-3): 225-232. Available from: http://dx.doi.org/10.1016/0257-8972(95)02486-7.

[12] Wu G., Li N., Zhou D.R., Mitsuo K. Electrodeposited Co-Ni- $\mathrm{Al}_{2} \mathrm{O}_{3}$ composite coatings. Surface and Coatings Technology. 2004; 176(2): 157-164. DOI: 10.1016/ s0257-8972(03)00739-4.

[13] Fundo A.M.B. do. Modificação de superfícies para aplicações em electrocatálise: deposição autocatalítica de ligas metálicas e incorporação de partículas de metais em matriz polimérica [thesis]. Lisboa, Portugal: Universidade de Lisboa; 2007. 174 p. Available from: http://hdl.handle.net/10451/1667.

[14] Lencina D.C., Ahrens C.H., Salmoria G.V., Lafratta F.H. Moldagem por injeção da PA 6.6 em moldes de estereolitografia metalizados com Ni-P pelo processo electroless. 
Polímeros: Ciência e Tecnologia 2007; 17(2): 88-92. DOI: 10.1590/ S0104-14282007000200006.

[15] Lee E.C., Choi J.W. A study on the mechanism of formation of electrocodeposited Nidiamond coatings. Surface and Coatings Technology. 2001; 148 (2-3): 234-240. DOI: 10.1016/S0257-8972(01)01352-4.

[16] Feng Q., Li T., Zhang Z., Zhang J., Liu M., Jin J. Preparation of nanostructured Ni/ $\mathrm{Al}_{2} \mathrm{O}_{3}$ composite coatings in high magnetic field. Surface and Coatings Technology. 2007; 201(14): 6247-6252. DOI: 10.1016/j.surfcoat.2006.11.019.

[17] Guo D., Zhang M., Jin Z., Kang R. Effect of direct current and pulse plating on the EDM performance of copper-zirconium diboride composites. Journal of University of Science and Technology Beijing, Mineral, Metallurgy, Material. 2007; 14(5): 464-468. DOI: 10.1016/S1005-8850(07)60091-7.

[18] Faraji S., Abdul Rahim A., Mohamed N., Sipaut C.S. A study of electroless copperphosphorus coatings with the addition of silicon carbide $(\mathrm{SiC})$ and graphite $(\mathrm{Cg})$ particles. Surface and Coatings Technology. 2011; 206(6): 1259-1268. DOI: 10.1016/ j.surfcoat.2011.08.032.

[19] Sánchez F.A.L., Reifler F.A., Clemens F., Amico S.C., Bergmann C.P. Obtenção de um revestimento compósito de poliéster-uretana reforçado com alumina pela técnica de deposição por imersão sobre fibras de poliamida 6. Cerâmica. 2009; 55: 379-384. DOI: 10.1590/S0366-69132009000400007.

[20] Tao Y., Xiong T., Sun C., Jin H., Du H., Li T. Effect of $\alpha-\mathrm{Al}_{2} \mathrm{O}_{3}$ on the properties of cold sprayed $\mathrm{Al} / \alpha-\mathrm{Al}_{2} \mathrm{O}_{3}$ composite coatings on AZ91D magnesium alloy. Applied Surface Science. 2009; 256(1): 261-266. DOI: 10.1016/j.apsusc.2009.08.012.

[21] Wu B., Xu B.-S., Zhang B., Lü Y.-H. Preparation and properties of Ni/nano- $\mathrm{Al}_{2} \mathrm{O}_{3}$ composite coatings by automatic brush plating. Surface and Coatings Technology. 2007; 201(16-17): 6933-6939. DOI: 10.1016/j.surfcoat.2006.12.022.

[22] Cordero-Arias L., Boccaccini A.R., Virtanen S. Electrochemical behavior of nanostructured $\mathrm{TiO}_{2}$ /alginate composite coating on magnesium alloy AZ91D via electrophoretic deposition. Surface and Coatings Technology. 2015; 265: 212-217. DOI: 10.1016/ j.surfcoat.2015.01.007.

[23] Garcia I., Fransaer J., Celis J.P. Electrodeposition and sliding wear resistance of nickel composite coatings containing micron and submicron $\mathrm{SiC}$ particles. Surface and Coatings Technology. 2001; 148(2-3): 171-178. DOI: 10.1016/S0257-8972(01)01336-6.

[24] Thiemig D., Bund, A. Influence of ethanol on the electroco-deposition of $\mathrm{Ni} / \mathrm{Al}_{2} \mathrm{O}_{3}$ nanocomposite films. Applied Surface Science. 2009; 255(7): 4164-4170. DOI: 10.1016/ j.apsusc.2008.10.114. 
[25] Aruna S.T., Grips V.K.W., Rajam K.S. Synthesis and characterization of $\mathrm{Ni}-\mathrm{Al}_{2} \mathrm{O}_{3}$ composite coatings containing different forms of alumina. Journal of Applied Electrochemistry. 2010; 40(12): 2161-2169. DOI: 10.1007/s10800-010-0198-3.

[26] Garcia I., Conde A., Langelaan G., Fransaer J., Celis J.P. Improved corrosion resistance through microstructural modifications induced by codepositing SiC-particles with electrolytic nickel. Corrosion Science. 2003; 45(6): 1173-1189. DOI: 10.1016/ S0010-938X(02)00220-2.

[27] Malfatti C.F. Elaboração e Caracterização de Nanocompósitos Ni-P-SiC Eletrodepositados [thesis]. Porto Alegre, RS: Universidade Federal do Rio Grande do Sul; 2004. 147 p. Available from: http://hdl.handle.net/10183/4451.

[28] Malfatti C.F., Veit H.M., Menezes T.L., Ferreira J.Z., Rodrigues J.S., Bonino J.P. The surfactant addition effect in the elaboration of electrodepositated NiP-SiC composite coatings. Surface and Coatings Technology. 2007; 201(14): 6318-6324. DOI: 10.1016/ j.surfcoat.2006.11.040.

[29] Martins D.F. Estudo de banhos ácidos para substituição de banho alcalino cianídrico na eletrodeposição de zinco sobre pregos [dissertation]. Porto Alegre, RS: Universidade Federal do Rio Grande do Sul; 2009. 142 p. Available from: http:// hdl.handle.net/10183/18587.

[30] Lima F.A.S. Eletrodeposição de filmes finos de CdTe para aplicação em células solares fotovoltaicas [dissertation]. Fortaleza, CE: Universidade Estadual do Ceará; 2010. 114 p.

[31] Paunovic M., Schlesinger M. Fundamentals of Electrochemical Deposition. $2^{\text {nd }}$ ed. New York: John Wiley \& Sons; 2006. 373 p.

[32] Wolynec S. Técnicas Eletroquímicas em Corrosão. $1^{\text {st }}$ ed. São Paulo, SP: EDUSP; 2013. $176 \mathrm{p}$.

[33] Neckel I.T. Crescimento e morfologia de ligas CoxFe100-x Eletrodepositadas sobre Si(111) tipo-n [dissertation]. Curitiba, PR: Universidade Federal do Paraná; 2009. 108 p. Available from: http://hdl.handle.net/1884/21180.

[34] Gurrappa I., Binder L. Electrodeposition of nanostructured coatings and their characterization-a review. Science and Technology of Advanced Materials. 2008; 9(4): 111. DOI: 10.1088/1468-6996/9/4/043001.

[35] Silva Jr A.I., Filho H.C.A., Silva R.C. Testes de desempenho de eletrodos: Eletrodos de referência. Química Nova. 2000; 23(4): 512-517. DOI: 10.1590/ S0100-40422000000400014.

[36] Borkar T., Harimkar S.P. Effect of electrodeposition conditions and reinforcement content on microstructure and tribological properties of nickel composite coatings. Surface and Coatings Technology. 2011; 205(17-18): 4124-4134. DOI: 10.1016/j.surfcoat.2011.02.057. 
[37] Shi L., Sun C., Gao P., Zhou F., Liu W. Mechanical properties and wear and corrosion resistance of electrodeposited $\mathrm{Ni}-\mathrm{Co} / \mathrm{SiC}$ nanocomposite coating. Applied Surface Science. 2006; 252(10): 3591-3599. DOI: 10.1016/j.apsusc.2005.05.035.

[38] Sohrabi A., Dolati A., Ghorbani M., Monfared A., Stroeve P. Nanomechanical properties of functionally graded composite coatings: Electrodeposited nickel dispersions containing silicon micro- and nanoparticles. Materials Chemistry and Physics. 2010; 123(2-3): 829-829. DOI: 10.1016/j.matchemphys.2010.04.040.

[39] Sombatsompop N., Sukeemith K., Markpin T., Tareelap N. A new experimental apparatus of electro-codeposited system for Ni-WC composite coatings. Materials Science and Engineering: A. 2004; 381(1-2): 175-188. DOI: 10.1016/j.msea.2004.04.017.

[40] Li J., Sun Y., Sun X., Qiao J. Mechanical and corrosion-resistance performance of electrodeposited titania-nickel nanocomposite coatings. Surface and Coatings Technology. 2005; 192(2-3): 331-335. DOI: 10.1016/j.surfcoat.2004.04.082.

[41] Battisti L.C. Influência do pH e da velocidade de agitação do banho de eletrodeposição no desempenho de revestimentos de zinco e zinco-nanocompósitos [dissertation]. Novo Hamburgo, RS: Universidade Feevale; 2011. 80 p.

[42] Takahashi A., Miyoshi Y., Hada T. Structure of electrodeposited Zn-7 wt\% Cr alloy. Journal of the Surface Finishing Society of Japan. 1994; 45(3): 301-306. DOI: 10.4139/ sfj.45.301.

[43] Sajjadnejad M., Omidvar H., Javanbakht M., Pooladi R., Mozafar A. Direct current electrodeposition of $\mathrm{Zn}$ and $\mathrm{Zn}-\mathrm{SiC}$ nanocomposite coatings. Transactions of the IMF. 2014; 92(4): 227-232. DOI: 10.1179/0020296714Z.000000000187.

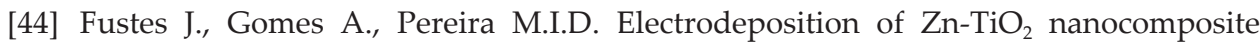
films-effect of bath composition. Journal of Solid State Electrochemistry. 2008; 12(11): 1435-1443. DOI: 10.1007/s10008-007-0485-z.

[45] Zamblau I., Varvara S., Muresan L.M. Corrosion behaviour of $\mathrm{Cu}^{-\mathrm{SiO}_{2}}$ nanocomposite coatings obtained by electrodeposition in the presence of cetyltrimethyl ammonium bromide. Journal of Materials Sicence. 2011; 46(20): 6484-6490. DOI: 10.1007/ s10853-011-5594-5.

[46] Eroglu D., Vilinska A., Somasundaran P., West A.C. Use of dispersants to enhance incorporation rate of nano-particles into electrodeposited films. Electrochimica Acta. 2013; 113: 628-634. DOI: 10.1016/j.electacta.2013.09.113.

[47] Sen R., Das S., Das K. Effect of stirring rate on the microstructure and microhardness of $\mathrm{Ni}-\mathrm{CeO}_{2}$ nanocomposite coating and investigation of the corrosion property. Surface and Coatings Technology. 2011; 205(13-14): 3847-3855. DOI: 10.1016/j.surfcoat. 2011.01.057. 
[48] Kim S.K., Yoo H.J. Formation of bilayer Ni-SiC composite coatings by electrodeposition. Surface and Coatings Technology. 1998; 108-109(0): 564-569. DOI: 10.1016/ S0257-8972(98)00589-1.

[49] Baghery P., Farzam M., Mousavi A.B., Hosseini M. Ni- $\mathrm{TiO}_{2}$ nanocomposite coating with high resistance to corrosion and wear. Surface and Coatings Technology. 2010; 204(23): 3804-3810. DOI: 10.1016/j.surfcoat.2010.04.061.

[50] Bund A., Thiemig D. Influence of bath composition and $\mathrm{pH}$ on the electroco-deposition of alumina nanoparticles and nickel. Surface and Coatings Technology. 2007; 201(16-17): 7092-7099. DOI: 10.1016/j.surfcoat.2007.01.010.

[51] Lekka M., Zendron G., Zanella C., Lanzutti A., Fedrizzi L., Bonora P.L. Corrosion properties of micro- and nanocomposite copper matrix coatings produced from a copper pyrophosphate bath under pulse current. Surface and Coatings Technology. 2011; 205(11): 3438-3447. DOI: 10.1016/j.surfcoat.2010.12.003.

[52] Silva F.L.G., et al. Response surface analysis to evaluate the influence of deposition parameters on the electrodeposition of Cu-Co alloys in citrate medium. Journal of Applied Electrochemistry. 2008; 38(12): 1763-1769. DOI: 10.1007/s10800-008-9630-3.

[53] Lee H.-K., Lee H.-Y., Jeon J.-M. Co-deposition of micro- and nano-sized SiC particles in the nickel matrix composite coatings obtained by electroplating. Surface and Coatings Technology. 2007; 201(8): 4711-4717. DOI: 10.1016/j.surfcoat.2006.10.004.

[54] Stojak J.L., Talbot J.B. Investigation of electrocodeposition using a rotating cylinder electrode. Journal of the Electrochemical Society. 1999; 146(12): 4504-4513. DOI: 10.1149/1.1392665.

[55] Sun K.-N., Hu X.-N., Zhang J.-H., Wang J.-R. Electrodeposited $\mathrm{Cr}-\mathrm{Al}_{2} \mathrm{O}_{3}$ composite coating for wear resistance. Wear. 1996; 196(1-2): 295-297. DOI: 10.1016/0043-1648(95)06860-0.

[56] Roventi G., Bellezze T., Fratesi R. Electrodeposition of Zn-SiC nanocomposite coatings. Journal of Applied Electrochemistry. 2013; 43(8): 839-846. DOI: 10.1007/ s10800-013-0571-0.

[57] Daltin D. Tensoativos: Química, Propriedade e Aplicações. São Paulo: Edgard Blucher; 2011.

[58] Hovestad A., Janssen L.J.J. Electrochemical co-deposition of inert particles in a metallic matrix. Journal of Applied Electrochemistry. 1995; 25(6): 519-527. DOI: 10.1007/ bf00573209.

[59] Ghorbani M., et al. Electro deposition of graphite-brass composite coatings and characterization of the tribological properties. Surface and Coatings Technology. 2001; 148(1): 71-76. DOI: 10.1016/s0257-8972(01)01322-6. 
[60] Iwakura C., Furukawa N., Tanaka M. Electrochemical preparation and characterization of $\mathrm{Ni} /\left(\mathrm{Ni}+\mathrm{RuO}_{2}\right)$ composite coatings as an active cathode for hydrogen evolution. Electrochimica Acta. 1992; 37(4): 757-758. DOI: 10.1016/0013-4686(92)80081-V.

[61] Lima T.G. Eletrodeposição de revestimentos funcionais compósitos $\mathrm{Cu} /$ partículas de óxidos de alumínio [dissertation]. Rio de Janeiro, RJ: Universidade do Estado do Rio de Janeiro; 2013. 155 p.

[62] Aruna S.T., Grips V.K.W., Rajam K.S. Synthesis and characterization of $\mathrm{Ni}-\mathrm{Al}_{2} \mathrm{O}_{3}$ composite coatings containing different forms of alumina. Journal of Applied Electrochemistry. 2010; 40(12): 2161-2169. DOI: 10.1007/s10800-010-0198-3.

[63] Guglielmi N. Kinetics of the deposition of inert particles from electrolyte baths. Journal of Applied Electrochemical. 1972; 119(8): 1009-1012. DOI: 10.1149/1.2404383.

[64] Celis J.P., Roos J.R., Buelens C. A mathematical model for the electrolyte co-deposition of particles with a metallic matrix. Journal of Applied Electrochemical. 1987; 134(6): 1402-1408. DOI: 10.1149/1.2100680.

[65] Oliveira R.S., Pinheiro M.A.S. Caracterização de Materiais Compósitos. In: XI CREEM; 30 de agosto a 3 de setembro; Nova Friburgo, RJ. 2004.

[66] Zheng H.-Y., An M.-Z. Electrodeposition of $\mathrm{Zn}-\mathrm{Ni}_{-} \mathrm{Al}_{2} \mathrm{O}_{3}$ nanocomposite coatings under ultrasound conditions. Journal of Alloys and Compounds. 2008; 459(1-2): 548552. DOI: 10.1016/j.jallcom.2007.05.043.

[67] Souza E.A. Avaliação de inibidores de corrosão para sistemas de resfriamento industrial operando com ciclo elevado de concentração [dissertation]. Rio de Janeiro, RJ: Universidade Federal do Rio de Janeiro; 2007. 114 p.

[68] Brandes E.A., Goldthorpe D. Electrodeposition of cermets. Metallurgia. 1967; 76(11): 195-198.

[69] Withers J.C. Electrodepositing cermets. Products Finishing. 1962; 26(11): 62-68.

[70] Martin P.W., Williams R.V. Proc. Interfinish. British Iron and Steel Research Association, London; 1964. 64, p. 182-188.

[71] Foster J., Kariapper A.M.J. Transactions of the IMF. 1973; 51: 27-31.

[72] Tsay P., Hu C.C. Non-anomalous co-deposition of iron-nickel alloys using pulse reverse electroplating through means of experimental strategies. Journal of Electrochemical Society. 2002; 149(10): C492-C497. DOI: 10.1149/1.1504718.

[73] Chang S.-C., Shieh J.M., Dai B.-T., Feng M.-S. The effect of plating current densities on self-annealing behaviours of electroplated copper films. Journal of Electrochemical Society. 2002; 149(9): G535-G538. DOI: 10.1149/1.1500348. 
[74] Yoshimura S., Yoshihara S., Shorakashi T., Sato E. Preferred orientation and morphology of electrodeposited iron from iron(II) chloride solution. Electrochimica Acta. 1994; 39(4): 585-595. DOI: 10.1016/0013-4686(94)80105-3.

[75] Zhargami V., Ghorbani M. Alteration of corrosion and nanomechanical properties of pulse electrodeposited Ni/SiC nanocomposite coatings. Journal of Alloys and Compounds. 2014; 598: 236-242. DOI: 10.1016/j.jallcom.2014.01.220.

[76] Praveen B.M., Venkatesha T.V. Electrodeposition and properties of Zn-nanosized $\mathrm{TiO}_{2}$ composite coatings. Applied Surface Science. 2008; 254(8): 2418-2424. DOI: 10.1016/j.apsusc.2007.09.047.

[77] Dorri-Moghadam A., Schultz B.F., Ferguson J., Omrani E., Rohatgi P.K., Gupta N. Functional metal matrix composites: self-lubricating, self-healing, and nanocomposites-an outlook. Journal of the Minerals, Metals and Materials. 2014; 66(6): 872-881. DOI: 10.1007/s11837-014-0948-5.

[78] Ferguson J., Sheykh-Jaberi F., Kim C.-S., Rohatgi P.K., Cho K. On the strength and strain to failure in particle-reinforced magnesium metal-matrix nanocomposites $(\mathrm{Mg}$ MMNCs). Material Science Engineering A. 2012; 558: 193-204. DOI: 10.1016/j.msea. 2012.07.111.

[79] Greef R., Peat R., Peter L.M., Pletcher D., Robinson J. Instrumental Methods and Electrochemistry. London: Woodhead Publishing; 1985. 442 p.

[80] Bard A.J., Faulkner L.R. Electrochemical Methods: Fundamentals and Applications. $2^{\text {nd }}$ ed. London: John Wiley \& Co; 2000. 864 p.

[81] Brett A.M.O., Brett C.M. Eletroquímica-Princípios, Métodos e Aplicações. $1^{\text {st }}$ ed. Coimbra, Portugal: Almedina Brasil; 1996. 472 p.

[82] Creus J., Mazille H., Idrissi H. Porosity evaluation of protective coatings onto steel through electrochemical techniques. Surface and Coatings Technology. 2000; 130(23): 224-232. DOI: 10.1016/S0257-8972(99)00659-3.

[83] Scully J.R., Taylor D.W. Electrochemical Methods of Corrosion Testing. $9^{\text {th }}$ ed. American Society for Metals; 1987; 13. 212 p.

[84] Wang S., Bradford S.A. Potentiodynamic polarization measurement by controlling potential inside a crevice. In: Bronson A., Warren G., editors. Techniques for Corrosion Measurement. Houston: National Association of Corrosion Engineers; 1992.

[85] Grundmeier G., Schmidt W., Stratmann M. Corrosion protection by organic coatings: electrochemical mechanism and novel methods of investigation. Electrochimica Acta. 2000; 45(15-16): 2515-2533. DOI: 10.1016/S0013-4686(00)00348-0.

[86] Olivier M.-G., Poelman M. Use of electrochemical impedance spectroscopy (EIS) for the evaluation of electrocoatings performances. In: Recent researches in corrosion evaluation and protection. Belgium: InTechOpen; 2012. p. 1-26. DOI: 10.5772/1843. 
[87] Szczygieł B., Kołodziej M. Composite Ni/ $\mathrm{Al}_{2} \mathrm{O}_{3}$ coatings and their corrosion resistance. Electrochimica Acta. 2005; 50(20): 4188-4195. DOI: 10.1016/j.electacta. 2005.01.040.

[88] Helle K., Walsh F. Electrodeposition of composite layers consisting of inert inclusions in a metal matrix. Transactions of the IMF. 1997; 75: 53-58. DOI: 10.1179/0020296713Z.000000000161.

[89] Katamipour A., Farzam M., Danaee I. Effects of sonication on anticorrosive and mechanical properties of electrodeposited $\mathrm{Ni}-\mathrm{Zn}-\mathrm{TiO}_{2}$ nanocomposite coatings. Surface and Coatings Technology. 2014; 254: 358-363. DOI: 10.1016/j.surfcoat.2014.06.043.

[90] Bryleva E.Y., Vodolazkaya N.A., Mchedlov-Petrossyan N.O., Samokhina L.V., Matveevskaya N.A., Tolmachev A.V. Interfacial properties of cetyltrimethylammoniumcoated $\mathrm{SiO}_{2}$ nanoparticles in aqueous media as studied by using different indicator dyes. Journal of Colloid Interface Science. 2007; 316(2): 712-722. DOI: 10.1016/j.jcis. 2007.07.03.

[91] Lekka M., et al. Mechanical and anticorrosive properties of copper matrix micro- and nano-composite coatings. Electrochimica Acta. 2009; 54(9): 2540-2546. DOI: 10.1016/ j.electacta.2008.04.060.

[92] Manahan S.E. Polarographic investigation of the allyl alcohol complex of copper(I) in aqueous solution. Inorganic Chemistry. 1966; 5(3): 482-483. DOI: 10.1021/ ic50037a034. 
